\title{
Space-time evolution of the rupture process from the inversion of strong-motion waveforms
}

\author{
Massimo Cocco and Francesca Pacor(*) \\ Istituto Nazionale di Geofisica, Roma, Italia
}

\begin{abstract}
This work aims to investigate the rupture history of the November 231980 , Irpinia earthquake $\left(M_{\mathrm{S}}=6.9\right)$. The distribution of slip and the behavior of rupture propagation are inferred by analyzing the strong-motion accelerograms. The fault geometry is constrained by geologic and geodetic data and by the aftershock distribution. isochrone approach with armal fault dipping $60^{\circ} \mathrm{NE}$. Theoretical seismograms have been computed using the Green's functions. The compatially variable slip intensity. Asymptotic ray theory is used to evaluate the far-field a rupture model updated following a trial-and-error a waveforms and synthetic ground velocities, computed by earthquake rupture. The source model resulting from appoach, allows one to point out several peculiarities of the used as a starting model for the inversion of grom the solution of the forward waveform modeling was then for slip velocity and rupture times on the fault by iteratively per Therefore, we performed a linearized inversion problem is solved by means of a tomographic back-projection bilateral rupture which does not propagate uniformly away from thnique. The inferred source model shows a is delayed about two seconds with respect to the SE away from the hypocenter. The NW rupture propagation slip distribution over the fault plane art to the SE rupture propagation. Moreover, the rupture velocity and the dislocation gap in the central part of the fault (Sele Valley) as suggested confirms the hypothesis of a shallow The results indicate that the rupture propagated nele Valley) as suggested by the behavior of the surface breakage. evidence was observed.
\end{abstract}

\section{Introduction}

The accelerograms recorded during the 1980 Irpinia earthquake represent a unique data set to investigate the rupture process on normal faults. Despite of its complexity, a detailed reconstruction of the faulting process was performed by different researchers during the past five years. These investigations were successfully carried out thanks to a quite complete geophysical data set which includes seismometric data at teleseismic and local distances, strong-motion data, surface faulting observations and coseismic elevation changes (see Westaway and Jackson, 1987; Bernard and Zollo, 1989; Pantosti and Valensise, 1990). A question which remained unsolved concerns the dynamic behavior of slip and the rup- ture development on the fault plane during the earthquake. This work aims to investigate the rupture process of the Irpinia earthquake by inverting the ground-motion waveforms. The results obtained by the analysis of geologic, geodetic and seismometric data have been considered since they provide important physical constraints for the inversion problem. The strong-motion data are used to get an accurate picture of the space-time evolution of the rupture process.

In order to understand how we constrained the geometry of the faults that ruptured during the Irpinia event, we summarize some important results obtained in previous studies. The surface faulting was first reported by Westaway and Jackson (1984 and 1987) and later recognized 
over a broader area by Pantosti and Valensise (1990). Results from these studies allowed the identification of a fault scarp associated with the earthquake having a total length of $38 \mathrm{~km}$. Several fault fragments were identified analyzing the surface rupture, each of which was associated with the different rupture episodes of the Irpinia earthquake (fig. 1) which have been detected by the analysis of both teleseismic and accelerometric data. The source time function obtained at teleseismic distances (Bezzeghoud, 1987; Giardini, 1990) revealed that the rupture was characterized at least by three different episodes occurring at $0 \mathrm{~s}, 20 \mathrm{~s}$ and $40 \mathrm{~s}$. The accelerograms recorded at several sites clearly show two distinct events separated by a $40-\mathrm{s}$ time lag. Figure 1 shows the aftershock locations, the epicenters of the three largest events (denoted as $0 \mathrm{~s}, 20 \mathrm{~s}$ and $40 \mathrm{~s}$ subevents in the following) and the position of the fault fragments associated with these subevents (Pantosti and Valensise, 1990). The dashed line indicates the possible northwestward continuation of the rupture. This northwestward continuation of the rupture was originally proposed by Bernard and Zollo (1989) and it is constrained mainly by the strong-motion data. Bernard and Zollo (1989) used the waveforms recorded by the accelerographs to the NW to constrain the extent and the kinematic of this rupture episode. This topic will be further discussed in this work. Figure 1 also shows the focal mechanism of the Irpinia mainshock computed by Giardini et al. (1984). Almost identical solutions were obtained by other authors (Kanamori and Given, 1982;

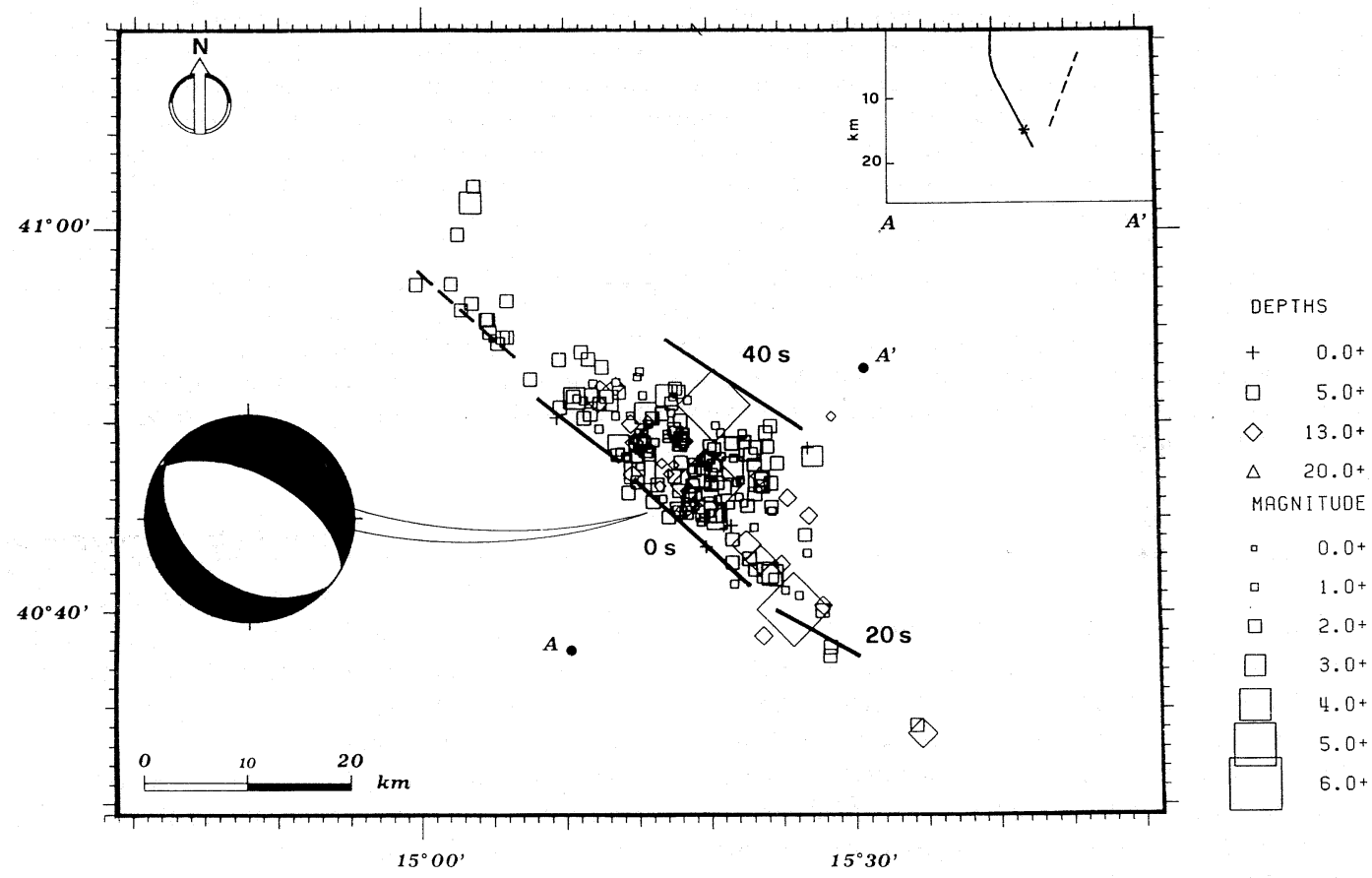

Fig. 1. Faulting model of the Irpinia earthquake. The map shows the distribution of epicentres of the relocated aftershocks and of the three main subevents indicated as $0 \mathrm{~s}, 20 \mathrm{~s}$ and $40 \mathrm{~s}$. The solid lines represent the four fault fragments activated during this earthquake which are mainly constrained by surface and leveling data (Pantosti and Valensise, 1990). In this figure the $0 \mathrm{~s}$ event is associated with two distinct fault fragments as suggested by the surface expression of the fault. These two fault fragments are separated by the Sele Valley that represents a gap in the surface slip. The dashed line indicates the possible NW extension of the earthquake rupture as suggested by strong-motion data. $\mathrm{AA}^{\prime}$ are the endpoints of the cross-section plotted in the box that shows the fault traces at depth. The faut plane solution of the Irpinia mainshock is taken from Giardini et al. (1984). 
Brustle and Müller, 1983; Del Pezzo et al., 1983). One well-constrained nodal plane has the strike around $315^{\circ}$ and dips about $60^{\circ}$ to the NE. Field observations, the analysis of leveling data and the aftershock distribution confirm that this is the real fault plane where the main rupture occurred. Westaway and Jackson (1987) and Bernard and Zollo (1989) computed the fault plane solutions also for the $20 \mathrm{~s}$ and $40 \mathrm{~s}$ subevents. All these solutions indicate that a complex system of normal faults was activated during the 1980 Irpinia sequence (see fig. 1) and that the amount of left-lateral strike-slip solution is negligible.

Only for the geometry of the main rupture $(0 \mathrm{~s})$ the agreement is unanimous (Crosson et al., 1986; Westaway and Jackson, 1987; Bernard and Zollo, 1989; Pantosti and Valensise, 1990; Siro and Chiaruttini, 1989; Suhadolc et al., 1990). The goal of this work is to study the evolution of the rupture process along the main fault; we believe that no more information on the source mechanism of the 20 s subevent may be extracted from the strong-motion records due to the poor source coverage. The uncertainties on fault geometry and the paucity of accelerograms complicate the theoretical modeling of the $40 \mathrm{~s}$ rupture.

\section{The strong-motion accelerograms}

\subsection{Spectral analysis}

The 1980 Irpinia earthquake triggered fifteen strong-motion accelerographs, eight of which lie within $50 \mathrm{~km}$ from the hypocenter and eleven accelerograms show a favourable signal-to-noise ratio. Table I includes a list of accelerometric stations, the hypocentral distances (from the earthquake location computed by Westaway and Jackson, 1987) and the peaks of horizontal ground acceleration. The largest peak acceleration was recorded at Sturno (STU). Figure 2 shows the distribution of strong-motion sites closest to the fault, and the velocity time histories observed at Calitri (CAL), Bagnoli (BAG), Sturno (STU), Mercato San Severino (MER), Bisaccia (BIS) and Auletta (AUL). The ground velocities have been computed from the recorded accelerograms using the exact deconvolution method of Alessandrini et al. (1990).
The strong-motion accelerograms were analysed in order to obtain a parameterization of the ground-motion spectrum in the frequency band of engineering interest (Rovelli et al., 1988), allowing the investigation of the effect of anelastic attenuation and local site response on the ground-motion waveforms. The analysis of the ground-motion attenuation in the frequency domain (see Anderson and Hough, 1984; Rovelli et al., 1988) revealed that the attenuation of high frequencies is almost comparable among the different sites with the exception of Bisaccia (BIS) where we observed a strong attenuation of the high-frequency radiation. The value of the attenuation parameter $\kappa$ (Anderson and Hough, 1984) measured at BIS is almost twice as large as the values computed from the accelerograms recorded at the other stations; this value can also be explained in terms of amplification of low-frequency amplitudes (see Rovelli et al., 1988, for further details). This effect is easily visible on the recorded time histories (fig. 2). A narrow-band site effect characterizes the acceleration spectrum at Mercato San Severino (MER) in the frequency interval $(1 \div 2) \mathrm{Hz}$. This effect has to be taken into account in any attempt to model the observed amplitudes of ground motion by means of synthetic signals. Furthermore, Bernard and Zollo (1988) concluded that the acceleration time histories observed at the available stations are significantly incoherent for frequencies higher than $3 \mathrm{~Hz}$ because of the choice of the frequency

Table I.

\begin{tabular}{lccc}
\hline \hline Station & Code & $R(\mathrm{~km})$ & $a_{p}(\mathrm{gal})$ \\
\hline Auletta & AUL & 27 & $59\left(^{*}\right)$ \\
Bagnoli & BAG & 24 & 174 \\
Calitri & CAL & 19 & 137 \\
Sturno & STU & 34 & 314 \\
Mercato & MER & 49 & 141 \\
Rionero & RIO & 35 & 102 \\
Bisaccia & BIS & 28 & 94 \\
Benevento & BEN & 60 & 60 \\
Brienza & BRI & 44 & $210\left(^{*}\right)$ \\
Tricarico & TRI & 73 & $47\left(^{*}\right)$ \\
Bovino & BOV & 53 & 49 \\
\hline
\end{tabular}

(') Radiated from the 20 s sub-event. 


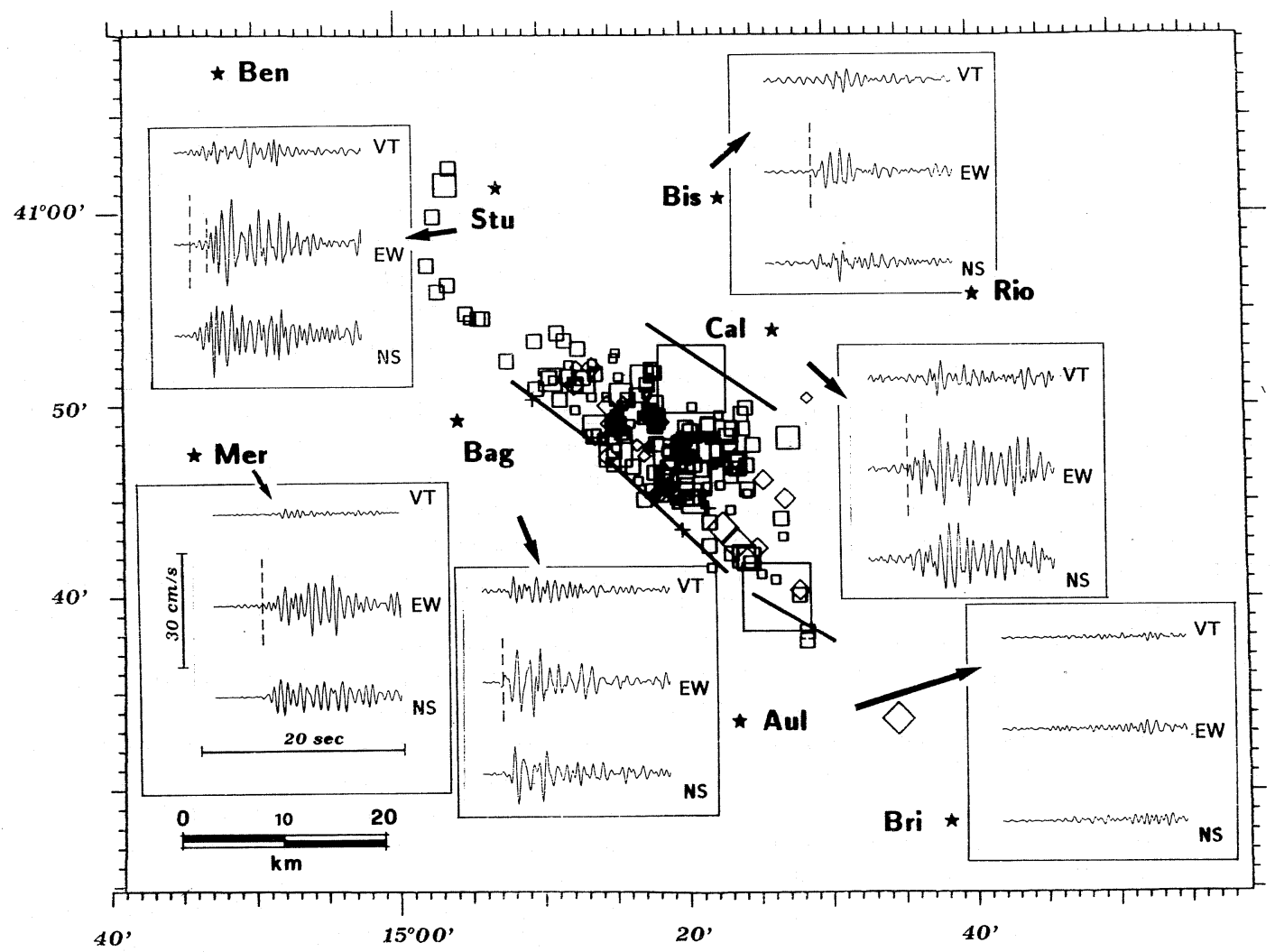

Fig. 2. Distribution of the strong-motion stations closest to the faults. The three components of the ground velocity recorded at BAG, MER, STU, CAL, BIS and AUL have been drawn in the boxes. All the traces are plotted with the same amplitude scale $(80 \mathrm{~cm} / \mathrm{s})$ and with the same duration $(20 \mathrm{~s})$. The ground velocity waveforms have been obtained from accelerograms using the approach proposed by Alessandrini et al. (1990). The time histories plotted in this figure are pass-band filtered between $(0.5 \div 2.0) \mathrm{Hz}$. Earthquake symbols are those drawn in fig. 1.

bandwith and/or of the small wavelength source heterogeneities. This observation limits the choice of the frequency bandwidth to be selected for the waveform modeling. For this reason, we low- pass filtered the strong-motion data with a cut-off frequency of $2.5 \mathrm{~Hz}$.

\subsection{Timing of accelerograms}

In order to study the rupture process we need to know the absolute time of each accelerogram. To solve this problem, we have computed the theoretical travel times from the hypocenter to the recording sites and we have read the arrival times of the different phases on the acceleration time histories. These analyses require the knowledge of the local velocity structure, of the hypocentral location and of the fault geometry, since the accelerographs may have been triggered by late wave arrivals rather than by the nucleation. Bernard and Zollo (1989) estimated the triggering time of the accelerograms by picking the $S$-wave arrivals for the $40 \mathrm{~s}$ subevent and by computing the theoretical travel times for a 1-D velocity model (see fig. 3 ). Table II shows the triggering times resulting from two different epicentral locations of the $40 \mathrm{~s}$ subevent pro- 


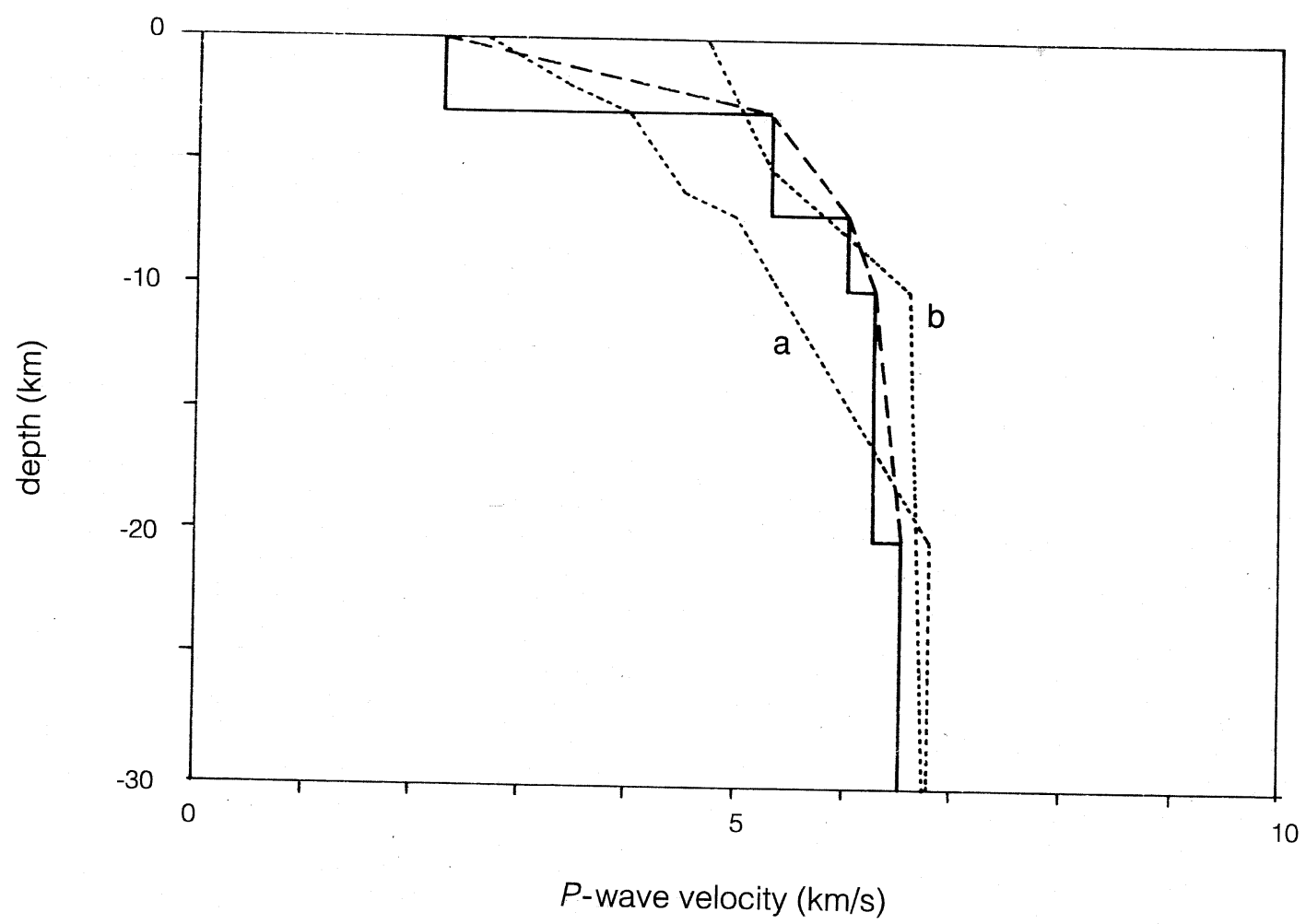

Fig. 3. $P$-wave velocity models for the Irpinia region. The solid line represents the velocity model used by Bernard and Zollo (1989). The dashed line indicates the gradient model deduced from the previous one. The dotted lines show the behavior of $P$-wave velocity inferred from tomographic inversion of travel time residuals (Amato and Selvaggi, 1990). The two lines are the velocity model deduced for Calitri (a) and for Bagnoli and
Sturno (b).

posed by Bernard and Zollo (1989). The velocity model used by Bernard and Zollo is characterized by a, 3-km-thick, low-velocity first layer. Recently, Amato et al. (1989) and Amato and Selvaggi (1990) computed a 3-D velocity model for $P$-waves using Thurber's (1983) technique for the inversion of local earthquake travel time residuals. This velocity model is characterized by the presence of a low-velocity zone beneath the Ofanto basin, where the station of Calitri is located, and beneath the Sele Valley; higher velocities were found in the Monte Marzano area where the main rupture nucleated. The low-velocity zone in the Ofanto Basin extends down to $10 \mathrm{~km}$ in depth (Amato et al., 1989). This observation allows one to explain both the longer duration observed on the accelerogram recorded at Calitri and the anomalous low-frequency content observed at Bisaccia as the effect of the lateral heterogeneities (see fig. 2). Figure 3 shows the $P$-wave velocity versus depth for the Bernard and Zollo velocity model with homogeneous flat layers, for a gradient model deduced from the previous one, and for two velocity models extrapolated from the 3-D crustal structure. These two models attempt to reproduce the crustal structure beneath Calitri and Bagnoli and Sturno, respectively. The travel times from several point sources, located along the fault plane, have been computed for the accelerometric sites using these velocity models. This helped us to identify the arrival times on the acceleration records of the phases radiated by different portions of the fault plane. The triggering times have been computed 


\begin{tabular}{lccc}
\hline \hline Station & BZ a) (s) & BZ b) (s) & this study (s) \\
\hline Auletta & 13.8 & 12.2 & 11.0 \\
Bagnoli & 7.3 & 8.0 & 8.4 \\
Calitri & 4.3 & 3.8 & 3.9 \\
Sturno & 7.6 & 8.8 & 8.8 \\
& & & 10.2 \\
Mercato & 10.8 & 11.5 & 11.5 \\
Rionero & 6.4 & 5.2 & 5.4 \\
Bisaccia & 4.9 & 5.6 & 5.0 \\
\hline
\end{tabular}

Table II. Triggering time.

both by picking the $S$-wave arrivals from the $0 \mathrm{~s}$ event on the accelerograms and by matching the observed waveforms with synthetic seismograms. In general, we found that the variations of travel times, related to changes in the wave velocity produce significant effect only on the triggering time estimated for the accelerogram recorded at CAL where the triggering time is reduced of about $35 \%$ when the low-velocity zone is extended at depth, as suggested by the tomographic inversion. The two values of triggering time estimated for STU and listed in table II arise from two possible picks of the $S$-wave arrival time on the accelerogram. All the triggering times of the other accelerograms computed using the velocity models shown in fig. 3 range within the interval defined by the two estimates proposed by Bernard and Zollo, which explains the agreement with the values estimated in this study (see table II).

\section{Modeling the strong-motion data}

\subsection{Fault geometry}

In this work, we constrain the fault geometry by using results from geological and geodetic investigations as well as aftershock data (Westaway and Jackson, 1987; Bernard and Zollo, 1989; Pantosti and Valensise, 1990) because we believe that the source geometry cannot be a part of the solution either of a forward waveform modeling or of a waveform inversion problem. We study only the main rupture $(0 \mathrm{~s}$ event in fig. 1 ). The goal is to model the waveforms radiated by a purely normal fault dipping $60^{\circ} \mathrm{NE}$ with a strike of $315^{\circ}$ (fig. 4). The first two subevents are separated by a strong barrier that impeded a continuous propagation of the rupture from the southern $0 \mathrm{~s}$ fault fragment to the $20 \mathrm{~s}$ one. The arrest of rupture propagation on this barrier and the subsequent nucleation on the $20 \mathrm{~s}$ fault make difficult any attempt to model the rupture propagation along the two fault fragments together as a single fault.

According to Pantosti and Valensise (1990) a discontinuity in the surface faulting occurred in the Sele Valley which led them to propose the faulting model shown in fig. 1 , where the main fault is characterized by two fragments divided by the Sele Valley. However, there are no evidences which confirm that this behavior is extended at depth: the deficit of slip that occurred in the Sele Valley could be due to local material properties, consequently the Sele Valley may be interpreted as a relaxation barrier (King, 1986) or as a zone of velocity strengthening (Tse and Rice, 1986; Marone and Scholz, 1988). For these reasons we preferred to model the rupture propagation along a single fault on which the slip distribution shows a gap in a region corresponding to the Sele Valley. The fault scarp observed at the surface gives a minimum value of fault length. A maximum value can be obtained by the area of aftershock activity that is roughly $60 \mathrm{~km}$ for the Irpinia sequence. Figure 4 summarizes the fault model used in this study to synthesize the waveforms radiated during the main event: in a first step we proposed a fault length of $28 \mathrm{~km}$, that corresponds to the surface rupture identified for the $0 \mathrm{~s}$ event by Pantosti and Valensise (1990). We cannot exclude that the rupture propagated further to the North-West without surface evidences; we will discuss in the last section a faulting model where the rupture is assumed to have propagated north-westward for several kilometers. Moreover, we assume that rupture nucleated at a depth of $10 \mathrm{~km}$ (epicentral coordinates are taken from Westaway and Jackson, 1987). The fault width has been taken equal to 15 $\mathrm{km}$, in agreement with the depth of aftershock activity. The aftershocks relocated with the 3-D crustal model (Amato et al., 1989; Amato and Selvaggi, 1990) are concentrated at a depth of 8 to $12 \mathrm{~km}$. Notewhorty is the absence of shallow seismicity in the Sele Valley and along the north- 

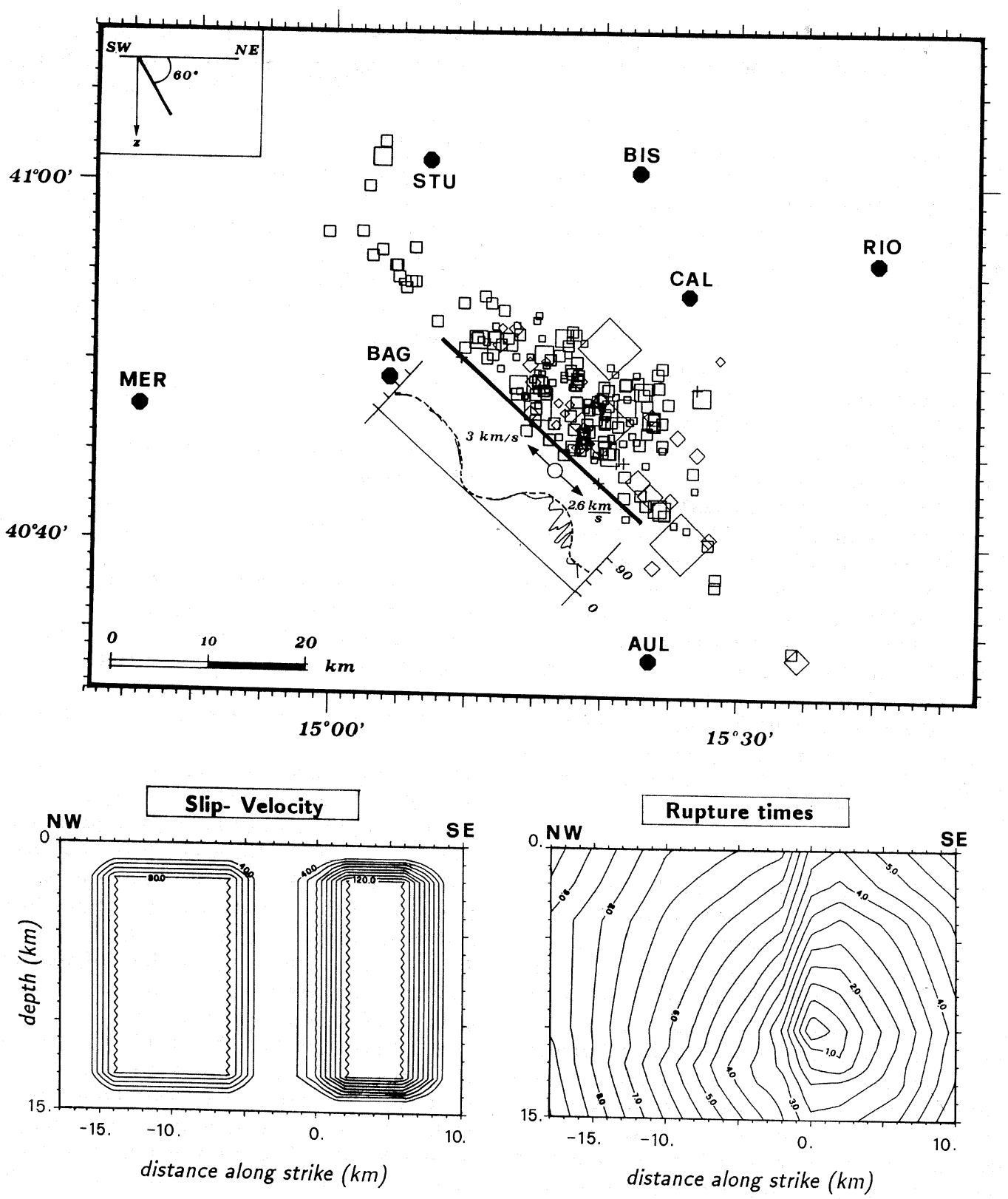

Fig. 4. Theoretical model used in this work for the forward waveform modeling. The plan view shows the surface trace of the theoretical fault dipping $60^{\circ} \mathrm{NE}$. The fault length is $28 \mathrm{~km}$ as resulting from the observed surface breakage; the fault width is $15 \mathrm{~km}$. The curve drawn close to the fault trace represents the fault scarp height measured by Pantosti and Valensise (1990). The distribution of the dip component of slip velocity shown in the figure has been deduced from the behavior of surface rupture. The distribution of rupture time has been optimized by solving the forward waveform modeling with a trial-and-error approach. The two arrows indicate the propagation of a bilateral rupture. Earthquake symbols are those used in fig. 1. 
west section of the fault that suggests the presence of lithological and rheological discontinuities.

Different estimates of seismic moment have been proposed by different authors (Boschi et al. 1981; Nakanishi and Kanamori, 1984; Giardini et al., 1984; Westaway and Jackson, 1987; Bernard and Zollo, 1989) for the total composite event $(0 \mathrm{~s}, 20 \mathrm{~s}$ and $40 \mathrm{~s})$ ranging between $1.5 \times$ $10^{26}$ dyne $\cdot \mathrm{cm}$ and $3 \times 10^{26}$ dyne $\cdot \mathrm{cm}$. Westaway and Jackson (1987), Bernard and Zollo (1989) and Pantosti and Valensise (1990) estimated the seismic moment of the main rupture event $(0 \mathrm{~s})$ : their values range between $8.7 \times 10^{25} \mathrm{dyne} \cdot \mathrm{cm}$ and $1.3 \times 10^{26}$ dyne $\cdot \mathrm{cm}$. If we assume a fault area of $(15 \times 28) \mathrm{km}^{2}$ (see fig. 4) the average slip on the fault ranges between $(60 \div 80) \mathrm{cm}$. However, the study of surface faulting indicates a heterogeneous distribution of slip over the main fault: the fault scarp height (Pantosti and Valensise, 1990) shows a maximum of surface slip in the Monte Marzano zone $(\approx 100 \mathrm{~cm})$, where the main rupture nucleated. After a gap in the surface rupture in the Sele Valley, the vertical throw along the fault scarp again increases to $80 \mathrm{~cm}$ in the northwest section of the fault (fig. 4). These results provide important constraints on slip values which we used to define a kinematic model of the Irpinia fault.

\subsection{Solution of the forward modeling}

We modeled the waveforms radiated by a two-dimensional fault by using a kinematic approach where the spatial distributions of the source parameters (slip and rupture time) are input data in the numerical procedure. Synthetic seismograms have been computed using the isochrone method proposed by Spudich and Frazer (1984). This approach uses the ray theory to compute the travel times and ray paths of body waves in a vertically layered medium. Following Spudich and Frazer (1984) the ground velocity $\dot{\boldsymbol{u}}^{C}(\boldsymbol{x}, t)$ is computed by means of the equation

$$
\dot{\boldsymbol{u}}^{C}(\boldsymbol{x}, t)=\dot{f}_{\mathrm{r}}(t) * \int_{\ell_{C}(\boldsymbol{x}, \boldsymbol{\xi}, t)} s_{\mathrm{r}}(\xi) G_{n}^{C} \dot{\ell}_{C} \mathrm{~d} \ell_{C}
$$

where $C=P$ or $S$ denotes the wave type, $G_{n}^{C}$ is the far-field traction at $\boldsymbol{\xi}$ on the fault due to a point force in the $n$-th direction with unit amplitude at $x$; and $\mathrm{d} \ell_{C}$ is the differential element of length along the isochrone $\ell_{C}(\boldsymbol{x}, \boldsymbol{\xi}, t)$ (Spudich and Frazer, 1984). For a given time $t$ along the seismograms the isochrone $\ell_{C}$ is a curve that defines the set of fault points for which the body wave radiation arrives at the receiver $x$ at the time $t$. Moreover, $\dot{\ell}_{C}$ represents the isochrone velocity which expresses the surface gradient on the fault plane of the sum of the propagation time $T_{C}$ and the rupture time $t_{\mathrm{r}}$

$$
\dot{\ell}_{C}(\xi, x, t)=\left|\nabla_{\xi}\left(t_{\mathrm{r}}(\xi)+T_{C}(\xi, x)\right)\right|^{-1}
$$

The source time function is described by the following slip-rate function:

$$
S(\xi, t)=\dot{f}_{\mathrm{r}}\left[t-t_{\mathrm{r}}(\xi)\right] s_{\mathrm{r}}(\xi)
$$

where $\boldsymbol{s}_{\mathrm{r}}(\boldsymbol{\xi})$ represents the slip intensity. The time dependence of slip-rate is represented by $\dot{f}_{\mathrm{r}}(t)$. We used a truncated inverse square-root time singularity (Beroza and Spudich, 1988)

$$
\dot{f}_{\mathrm{r}}(t)=\left(t-t_{\mathrm{r}}\right)^{-1 / 2}\left[H\left(t-t_{\mathrm{r}}\right)-H\left(t-t_{\mathrm{h}}\right)\right]
$$

where $t_{\mathrm{h}}$ is the time after rupture when a point on the fault stops slipping. This source time function for slip intensity arises from crack models of the earthquake rupture (Kostrov, 1966; Madariaga, 1976; Day, 1982). This function describes the time dependence by means of the rupture time $t_{\mathrm{r}}$ and the healing time $t_{\mathrm{h}}$; the rise time is given by $T=t_{\mathrm{h}}-t_{\mathrm{r}}$. In this work the rise time is fixed to be constant everywhere on the fault in order to reduce the number of source parameters.

For the computation of synthetic seismograms by means of eq. (1), one needs to define the slip intensity and rupture-time distributions on the fault plane. The far-field tractions are computed using ray theory Green's function (see Spudich and Frazer, 1984, for further details). Figure 4 depicts the theoretical model used in this study for the forward waveform modeling: the plane view shows the surface trace (solid straight line) of the theoretical fault and, for comparison, the observed surface-rupture trend (taken from Pantosti and Valensise, 1990). This figure shows the accelerometric stations and the aftershock loca- 
tions. The fault is a purely normal fault dipping $60^{\circ} \mathrm{NE}$, with $28 \mathrm{~km}$ of length and $15 \mathrm{~km}$ of width. Figure 4 also includes the spatial distribution of the dip component of slip intensity and the distribution of rupture time on the assumed fault plane. This source model was selected among many different models by fitting the observed waveforms following a trial-and-error approach. Two patches of slip have been deduced from the surface-faulting observations: the minimum of slip intensity in the middle part takes into account the lack of surface rupture in the Sele Valley. The rupture time distribution has been optimized among many models. The basic assumption that constrained these models was the observation of the evident difference of amplitudes and phases (see fig. 2) among the stations located toward the NW (BAG and STU) with respect to those located toward the SE (AUL). This difference can be explained as an effect of a bilateral rupture propagating with a different rupture velocity along the main fault. The total rupture duration is about $10 \mathrm{~s}$ in agreement with the corner frequency estimated from strong-motion data $\left(f_{\mathrm{c}}=\right.$ $0.12 \mathrm{~Hz}$ ) by Rovelli et al. (1988). A strong gradient delayed the rupture propagation towards the NW by about $2 \mathrm{~s}$. This delay is necessary to fit the strong-motion data.

In order to compare the synthetic velocity time histories with the observed data we have used the values of triggering times shown in table II. Except for Auletta (AUL) and Brienza (BRI), all the accelerograms recorded at the stations shown in fig. 2 were triggered by the $P$-waves radiated during the nucleation of the main rupture. Figures 5 and 6 show the velocity waveform fit at the stations of Mercato San Severino (MER), Bagnoli (BAG), Bisaccia (BIS) and Rionero (RIO). The ray theory Green's functions have been computed using the gradient wave-velocity model deduced from Bernard and Zollo (1989). Data have been pass-band filtered in the frequency band of $(0.5 \div 2.5) \mathrm{Hz}$. The choice of these cut-off frequencies is due to the validity of ray theory and to the incoherence of the ground acceleration at frequencies higher than $3 \mathrm{~Hz}$. The synthetic ground velocities have been computed using the source shown in fig. 4 with a constant rise time of $1 \mathrm{~s}$. This value of the rise time is chosen in order to reproduce the observed range of seismic moment for the main rupture of the Irpinia earthquake (Westaway and Jackson, 1987; Bernard and Zollo, 1989; Pantosti and Valensise, 1990). The proposed source model gives a value of seismic moment of $7.0 \times 10^{25} \mathrm{dyne} \cdot \mathrm{cm}$ when $T$ $=1 \mathrm{~s}$ and of $1.9 \times 10^{26} \mathrm{dyne} \cdot \mathrm{cm}$ when $T=2.5 \mathrm{~s}$.

The agreement between data and synthetics shown in fig. 5 and 6 is generally good considering both amplitudes and phases. The observed amplitudes are well reproduced by the synthetic data with the exception of MER where a strong site effect amplifies the amplitudes at $(1 \div 2) \mathrm{Hz}$. For this reason the ground velocity waveforms computed in this site have been multiplied by a factor of 5 , as suggested by the comparison between observed and theoretical omega-square spectra (Rovelli et al., 1988). The fit of the ground velocity observed at BIS (fig. 6) is quite satisfactory even if the strong low-frequency arrivals on the EW component are not well reproduced; this is probably due to the effect of the propagation in the thick low-velocity layers. Both fig. 5 and 6 include the isochrone distributions computed for those recording sites. The pattern of the isochrones indicates the region of the fault plane where the largest amplitudes have been radiated. Note the low isochrone gradient (large separation) that produces the larger amplitudes observed at BAG. For comparison note the smoother isochrone distribution associated with the farther stations. The fit of the waveforms recorded at Auletta is poor because this station was triggered by the $S$-waves radiated during the main rupture or by the $P$-waves radiated by the stopping of the rupture on the SE limit of the fault. In both cases only a few seconds of ground acceleration radiated during the main rupture have been written on the accelerograms recorded at Auletta. The resulting fit of the velocity time history is acceptable even if limited to a short signal duration. The main uncertanties in the solution of the forward modeling emerged when fitting the waveforms observed at Calitri and Sturno by means of the source model shown in fig. 4. The interpretation of the ground-motion waveforms recorded at these two sites plays an important role for what concerns the source model of the Irpinia earthquake. In particular, the synthetic velocity waveforms at Calitri do not reproduce the complexity of the observed time 
Mercato
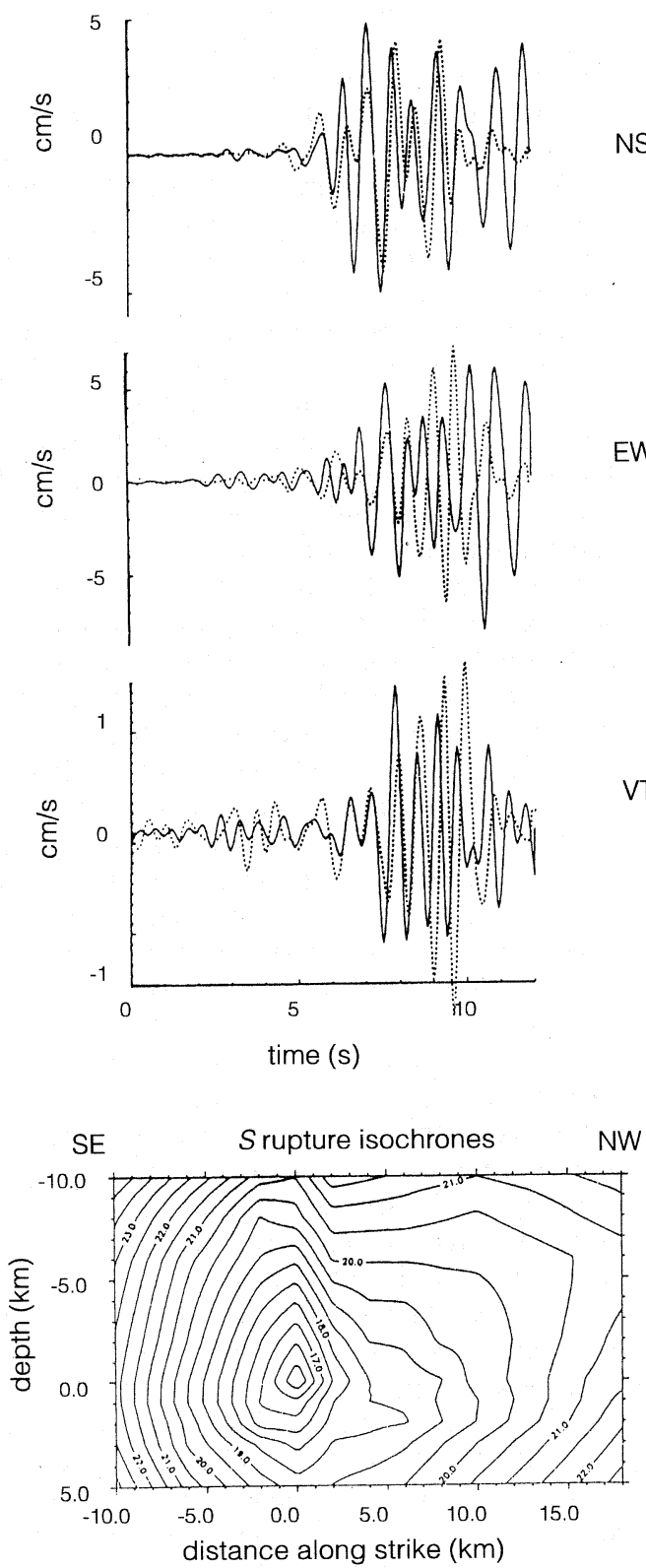

Bagnoli

NS

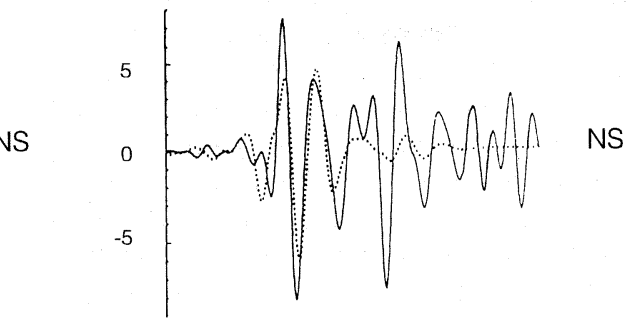

EW
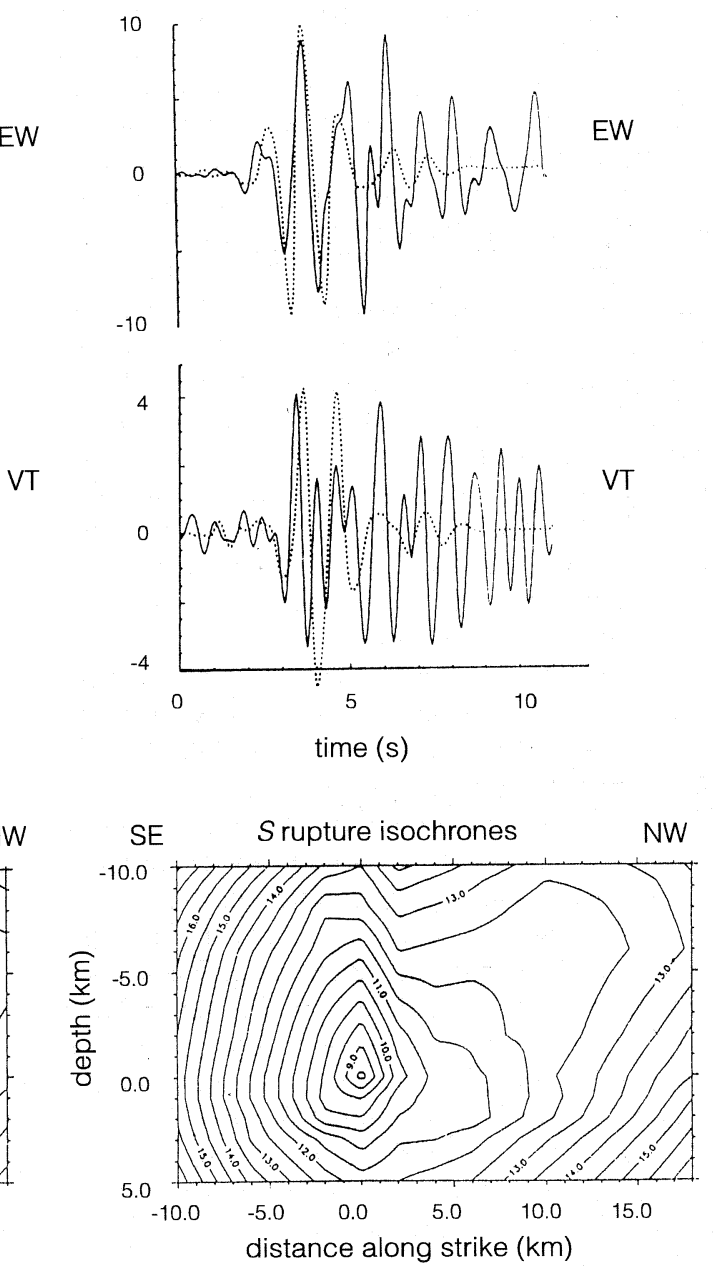

Fig. 5. Fit of the observed velocity waveforms (solid lines) with the synthetic time histories (dotted lines) computed from the theoretical model of fig. 4 using the isochrone approach (Spudich and Frazer, 1984). The $S$-wave isochrone distributions at MER and BAG are also shown on the bottom. The amplitudes of synthetic signals at MER are multiplied by a factor of 5 in agreement with the difference of amplitudes $(\mathrm{at} 1 \mathrm{~Hz})$ between observed spectra and theoretical omega-square spectra predicted in this site (Rovelli et al., 1988). 


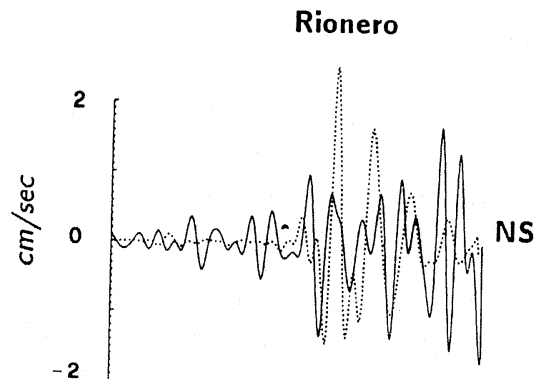

Bisaccia
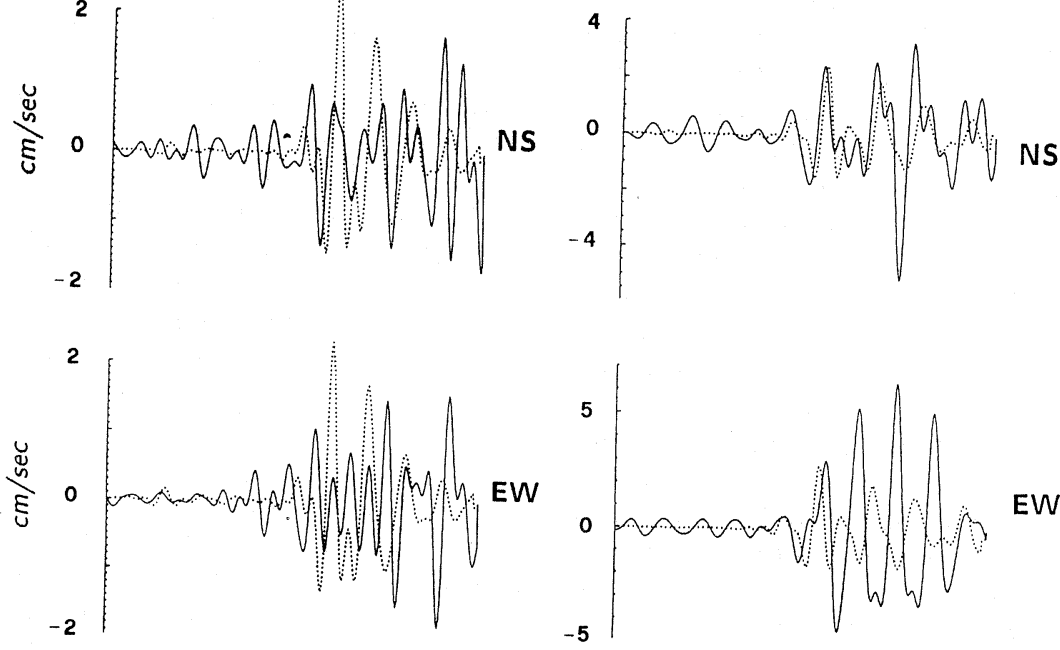

EW
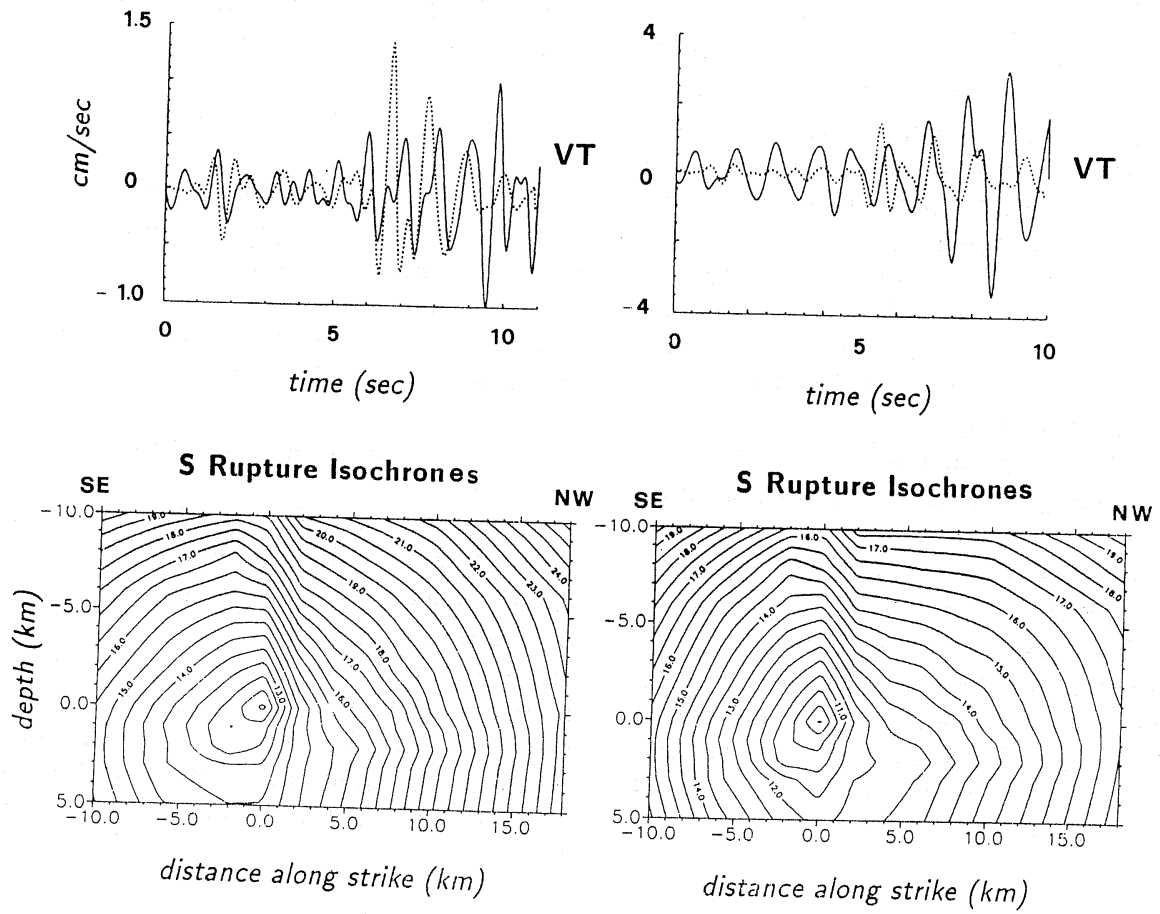

Fig. 6. Fit of the observed velocity waveforms (solid lines) with the synthetic time histories (dotted lines) $S$-wave isochrone distributions model of fig. 4 using the isochrone approach (Spudich and Frazer, 1984). The amplitudes on the EW component of BIS that are not reproduced by the bottom. Note the large low-frequency can be explained as the effect of the wave propagation in thed by the synthetic waveform. This disagreement 
histories. The disagreement between data and synthetics at Calitri could be explained in terms of the effect of unmodeled lateral heterogeneities which affect the wave propagation from the fault to the station. However, we cannot exclude that the source model used to compute the synthetic ground velocities should be modified in order to fit the waveforms observed at CAL and STU. The back projection on the fault plane of the geometrical spreading factor computed at Calitri shows that the seismic radiation is strongly dominated by the rupture behavior close to the nucleation zone. Another aspect which needs a careful discussion is the fit of Sturno. The synthetic waveforms fit some phases of the ground velocity observed at Sturno but a significant disagreement occurs for the largest amplitudes recorded on the horizontal components (fig. 7). The fit does not improve by complicating the rupture behavior. Among all the source models that have been tested to obtain an acceptable agreement between data and synthetics none of them was able to explain simultaneously the records of Bagnoli and Sturno. Our conclusion is that the phases associated with the largest amplitudes observed at Sturno are not reproduced by the rupture behavior along the proposed fault. We suggest that these phases could be radiated by the rupture propagation on a further fault fragment located on the northwestward continuation of the fault shown in fig. 4, as also proposed by Bernard and Zollo (1989). This is also suggested by the isochrone distribution shown in fig. 7 where the lower isochrone gradient occurs at the end of the proposed fault.

The forward waveform modeling enhanced several peculiarities of the rupture process during the main subevent of the Irpinia earthquake. The resulting source model must be improved before it can be proposed as a realistic description of the earthquake rupture. We believe that the best approach to this problem is the inversion of groundmotion waveforms.

\subsection{Solution of the inverse problem}

The rupture model resulting from the forward waveform modeling represents a good starting model to be iteratively perturbed in order to infer the rupture history of the Irpinia earthquake. We have used a linearized inverse approach to recover the spatial distribution of slip velocity and rupture time. The inversion procedure has been originally proposed by Beroza and Spudich (1988) to study the rupture behavior of the 1984 Morgan Hill, California, earthquake. This approach is based on the near-source representation of seismic source stated by eq. (1). The linearized inversion is needed because part of the model parameters have a nonlinear dependence on the data. The system of equations to be solved is

$$
g(m)=d
$$

where $\boldsymbol{d}$ is the data vector containing the seismograms, $\boldsymbol{m}$ is the model parameter vector whose components are the slip velocity and the rupture time. The operator $g$ represents the functional relation used to compute the synthetic seismograms from the model $\boldsymbol{m}$ (stated by eq. (1)). Equation (5) can be linearized as

$$
g(m+\delta m)=g(m)+A \delta m
$$

The matrix $\boldsymbol{A}$ contains the partial derivatives of theoretical seismograms with respect to the model parameters (see Beroza and Spudich, 1988, for further details). The model perturbation can be estimated using the least squares, minimum-norm generalized inverse $\boldsymbol{A}^{\dagger}$

$$
\delta m=A^{\dagger}[d-g(m)]
$$

The procedure developed by Beroza and Spudich (1988) to solve the nonlinear inverse problem consists in a set of iterations. In each iteration the model is updated by adding the computed perturbation to the previous model. The perturbation is calculated with an iterative back-projection technique because of the large size of $A$ (Beroza and Spudich, 1988). The iterative back projection algorithm can be expressed as (Olson, 1987)

$$
\delta \boldsymbol{m}=\sum_{k=1}^{K} \frac{1}{\sigma_{k}}\left[\boldsymbol{d}-\boldsymbol{g}\left(\boldsymbol{m}_{n-1}\right)-A_{n-1}^{\mathrm{T}} \delta \boldsymbol{m}_{n}^{k-1}\right]
$$

Here $\boldsymbol{A}^{\mathrm{T}}$ is the transpose of $\boldsymbol{A}$; and $\sigma_{k}$ is a weighting function which may vary during the iterations 

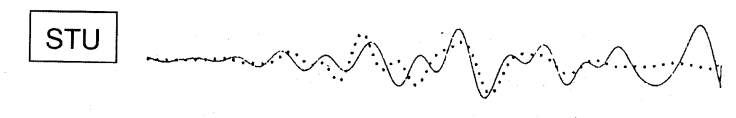

VT
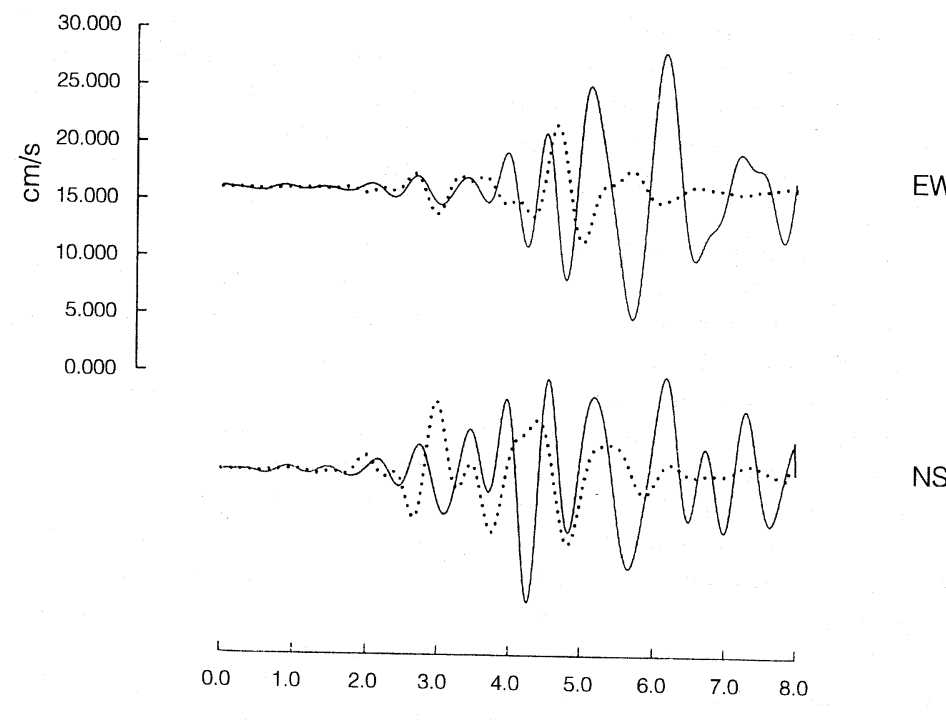

time (s)

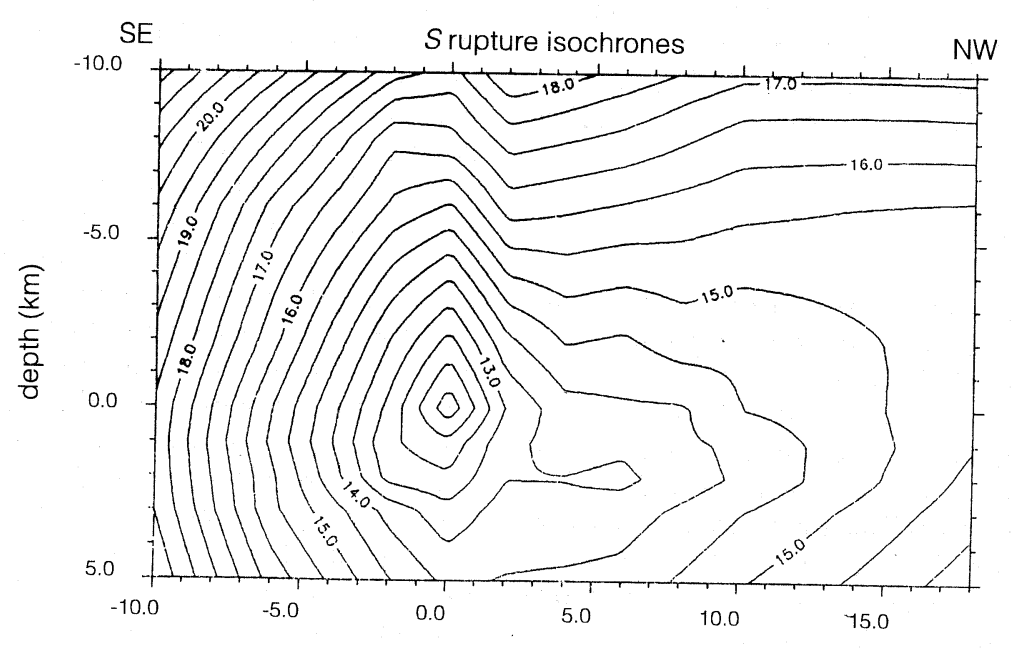

distance along strike $(\mathrm{km})$

Fig. 7. Fit of the observed velocity waveform (solid lines) with the synthetic time history (dotted lines) computed from the theoretical model of fig. 4 using the isochrone approach (Spudich and Frazer, 1984). The $S$-wave isochrone distribution at STU is also shown on the bottom. The largest amplitudes on the EW component are not reproduced by the synthetic signals. The isochrone distribution clearly shows that the largest separation between isochrone curves occur at the NW edge of the fault. This observation confirms our finding that the largest amplitudes at STU are radiated during the rupture on a further NW fault fragment. 
to achieve a rapid convergence (Olson, 1987). Equation (8) states that the perturbation to the $n$-th model is computed by a sequence of $K$ weighted back-projections of the residuals of the synthetics with respect to the data. This algorithm is used to improve the estimate of the model perturbation. This type of iterative back-projection method converges to the least-squares solution (Ivanson, 1983).

The procedure developed by Beroza and Spudich (1988) uses several constraints to produce a solution that is stable and feasible. First, the partial-derivative matrix $\boldsymbol{A}$ and the model perturbation $\delta \boldsymbol{m}$ are weighted because the rupture time and the slip velocity have different physical dimensions. The residuals have been normalized by a diagonal data covariance matrix. The normalization is necessary so that seismograms with large amplitudes will not dominate the solution. Moreover, the inequality constraint is used to avoid unfeasible solutions. A smoothness contraint is used on both the slip amplitude and the rupture time. The procedure uses the Chebyshev weighting scheme (Olson, 1987) to achieve uniform convergence over a prescribed range of eigenvalues. We have used sixteen iterations in eq. (8) and we have fixed the ratio between the largest to the smallest eigenvalue to a value of 25 .

\subsection{Resolution test}

As discussed in the previous section, we are going to solve the inverse problem for a normal fault whose length is larger than that used in the forward modeling $(28 \mathrm{~km})$. We assume that the rupture propagated northwestward for another 8 $\mathrm{km}$ in the same direction and with the same faulting mechanism of the main rupture for a total length of $36 \mathrm{~km}$. Bernard and Zollo (1989) discussed the uncertainties associated with the faulting mechanism of this later rupture.

In order to investigate the resolution on model parameters, we first applied the inversion procedure to synthetic data computed for a known source model. The resolution of the method is estimated using the same projection paths and weighting as in the real data. Figure 8 shows the known model which we used to compute the synthetic data. The rupture time distribution is taken from the results of the forward waveform modeling modified to extend the rupture to the last northwestward fragment. The dip component of slip velocity is homogeneously distributed on the fault plane $(100 \mathrm{~cm} / \mathrm{s})$ decreasing to zero on the border of the fault. The synthetic data seismograms have been generated by adding a random component to the rupture times shown in fig. 8 . This has been done with the aim of complicating the isochrone distribution at the different observers. In practice we randomly perturbed the isochrone times: the amplitude of the random component is $\pm 0.5 \mathrm{~s}$. This procedure simulates errors in the velocity model and the effects of an irregular rupture front development (Beroza and Spudich, 1988). Moreover, a random noise was added to the synthetic data seismograms before the inversion. The noise was a white noise with half the power of the synthetic data. Finally, we pass-band filtered the synthetics to resemble the actual data.

Figure 9 shows the source model resulting from the inversion. The area of largest slip velocity is well recovered with the exception of the region located between 10 and $15 \mathrm{~km}$ along the strike and at roughly $5 \mathrm{~km}$ of depth. The vertical extent of the high slip region is well resolved. The value of the largest slip velocity is $110 \mathrm{~cm} / \mathrm{s}$ in close agreement with the value in the original $\operatorname{model}(100 \mathrm{~cm} / \mathrm{s})$. We have used a rise time of 1 second and a source time function as defined in eq. (4). The perturbations to rupture times are not relevant and they tend to be larger in the regions of larger variations of slip velocity. The trade-off between changes in rupture time and changes in slip velocity (Spudich and Frazer, 1984) can be reduced only by introducing appropriate inequality constraints and weighting the model perturbations (Beroza and Spudich, 1988). We have performed other tests using different starting models. The results of the resolution tests indicate that the available station coverage for the Irpinia earthquake is sufficient to investigate the rupture history of the main rupture in the given distance and depth range.

\subsection{Data inversion}

Figure 10 shows the starting model that we 


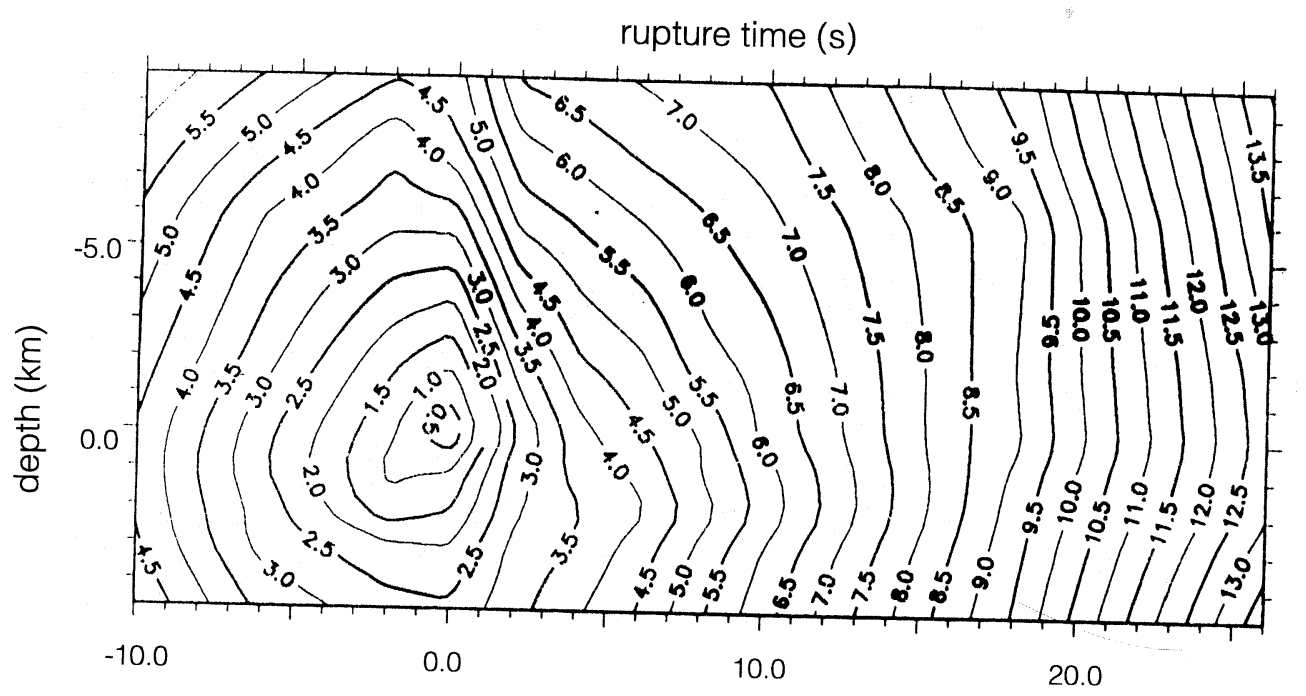

slip intensity $(\mathrm{cm} / \mathrm{s})$

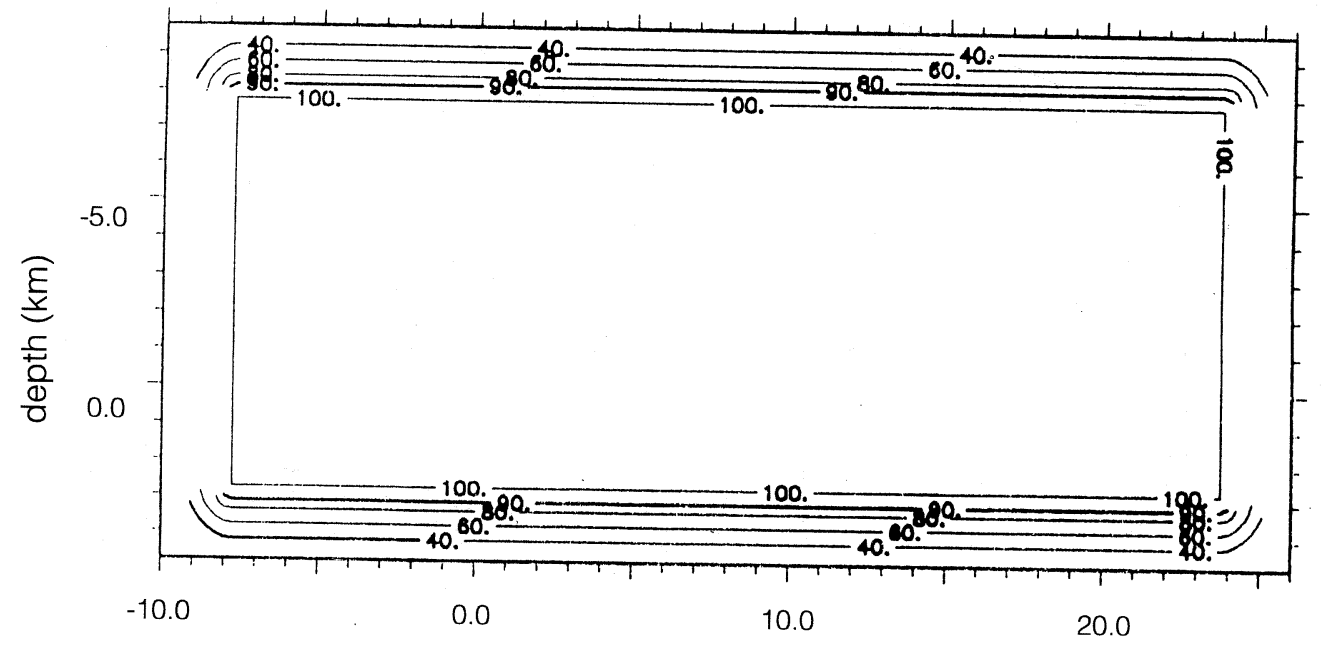

Fig. 8. Starting rupture model for synthetic resolution test. The rupture times are those resulting from the forward waveform modeling. The slip velocity is constant on the fault plane $(100 \mathrm{~cm} / \mathrm{s})$ and it decreases to zero
on the border.

used for the linearized inversion of ground-motion velocities consisting of two patches of slip velocity. A region of relative low slip velocity $(40 \mathrm{~cm} / \mathrm{s})$ has been located close to the NW edge of the fault (along the NW continuation of the main rupture); while a homogeneous distribution of slip velocity has been located on the remaining part of the fault. The rupture time distribution is that obtained from the forward waveform modeling and extended toward the NW. We have inverted the three components of the ground velocity recorded at the seven recording sites included in table II. The data have been pass-band filtered between 0.5 and $2.5 \mathrm{~Hz}$.

Figure 11 shows the source model obtained from the inversion of ground-motion waveforms. 


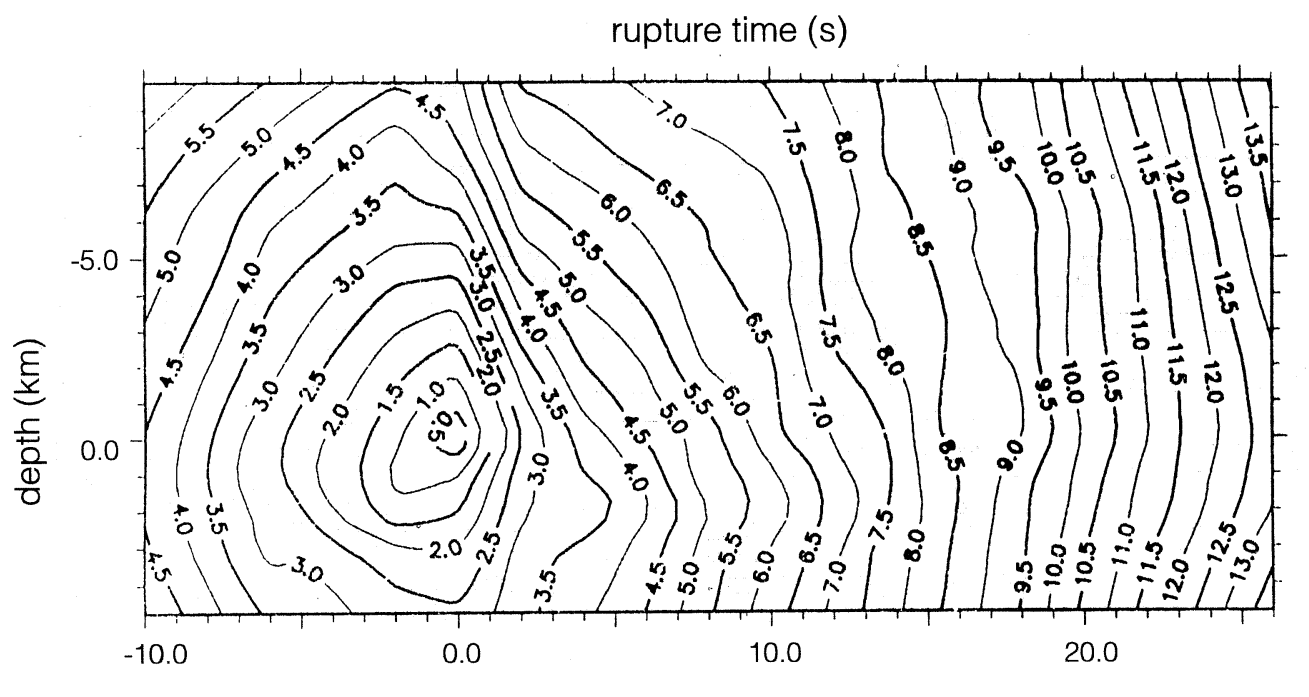

slip intensity $(\mathrm{cm} / \mathrm{s})$

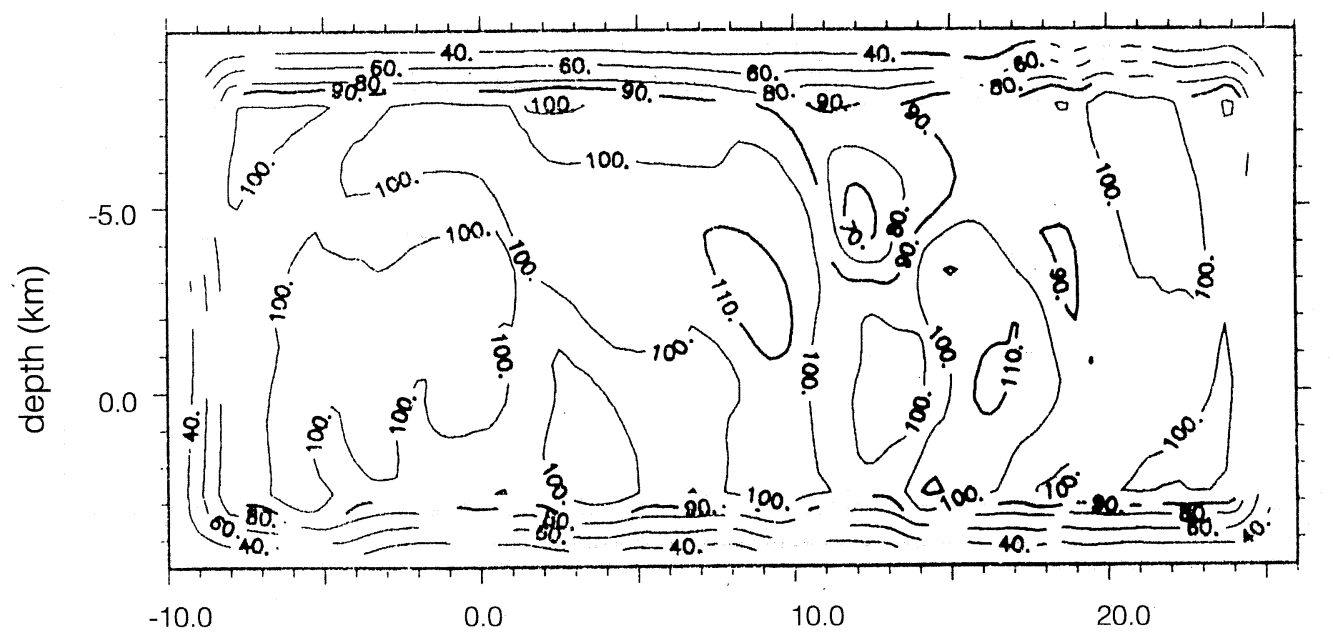

Fig. 9. Rupture model resulting from the inversion of synthetic data computed from fig. 8. The area of largest slip velocity is sufficiently well recovered with the exception of the region located between 10 and $15 \mathrm{~km}$ along the strike and at roughly $5 \mathrm{~km}$ of depth. The vertical extent of the high slip region is well resolved.

The fit to the data is shown in fig. 12. This model provides a satisfactory fit of BAG, CAL and STU. The slip velocity distribution in the model is strongly heterogeneous. There are three regions of higher slip velocity: the first one occurs in correspondence of the nucleation zone $(\approx 120$ $\mathrm{cm} / \mathrm{s}$ ) and it extends to shallow depth (fig. 11).
This result agrees both with the largest values of the fault scarp observed at the surface (Westaway and Jackson, 1987; Pantosti and Valensise, 1990) and with the shallow depth seismicity found in this zone (Bernard and Zollo, 1989; Amato and Selvaggi, 1990) (fig. 13). The second region $(\approx 90 \mathrm{~cm} / \mathrm{s})$ is located $14 \mathrm{~km} \mathrm{NW}$ away from the 

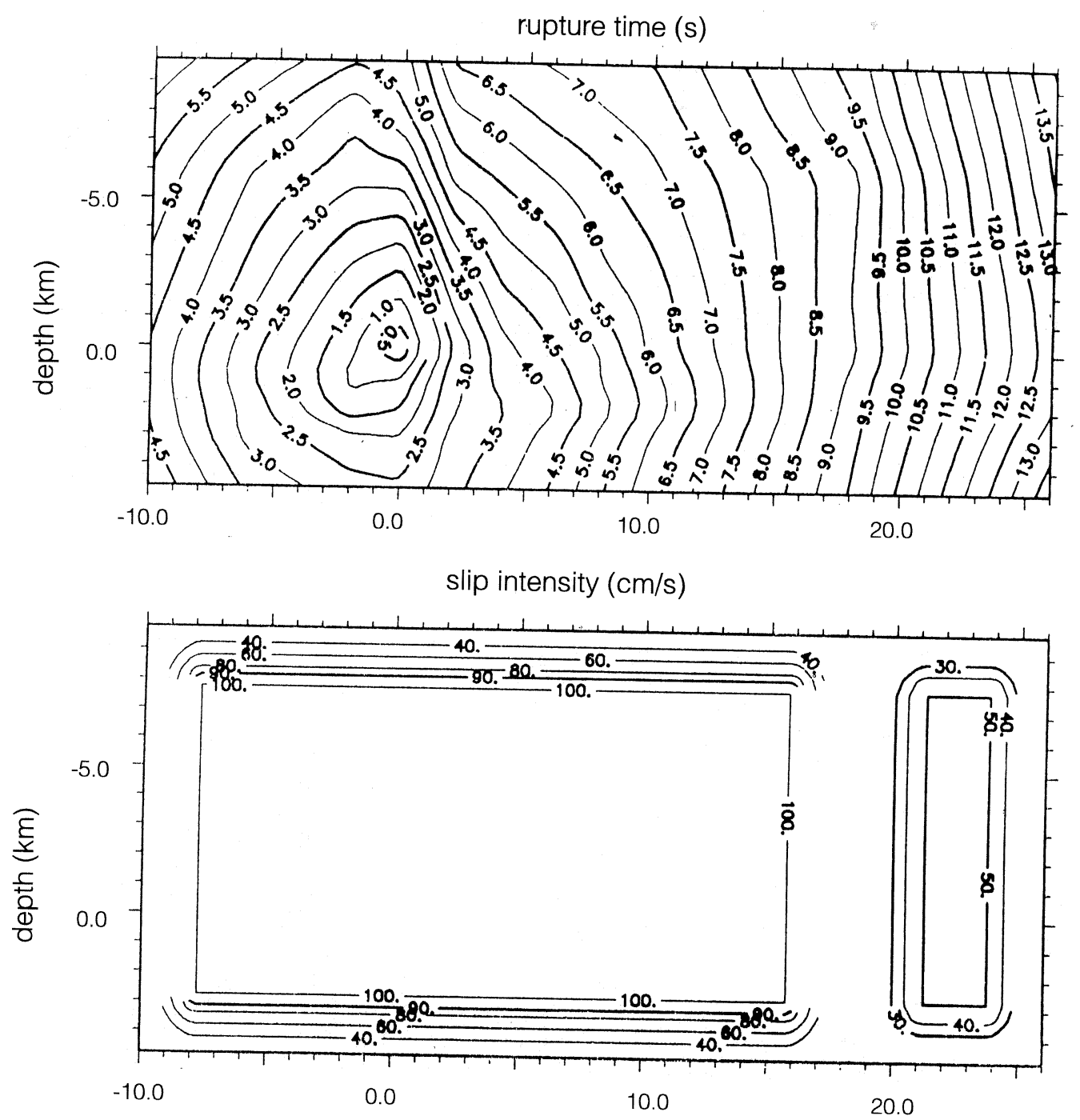

Fig. 10. Starting model for data inversion. The rupture times are those resulting from the forward waveform modeling. The slip velocity distribution consists in two patches: the first one homogeneously covers the portion of the fault plane modeled with the forward approach; the second patch is located on the NW extension of earthquake rupture.

nucleation point (fig. 11). This patch should correspond to the Picentini mountains fault scarp found by Pantosti and Valensise (1990) (fig. 13). This value of slip velocity could be underestimated because of the lower data resolution on this zone (fig. 9). Noteworthy is the decreasing of slip in the central part of the fault that roughly corre- sponds to the Sele Valley (fig. 13) where no surface slip has been observed. This region is characterized by the absence of shallow seismicity and by low wave velocities in the upper 5 $\mathrm{km}$. On the contrary, a cluster of aftershocks is observed at depth of 8 to $12 \mathrm{~km}$ beneath the Sele Valley (fig. 13). The last region of relative high 


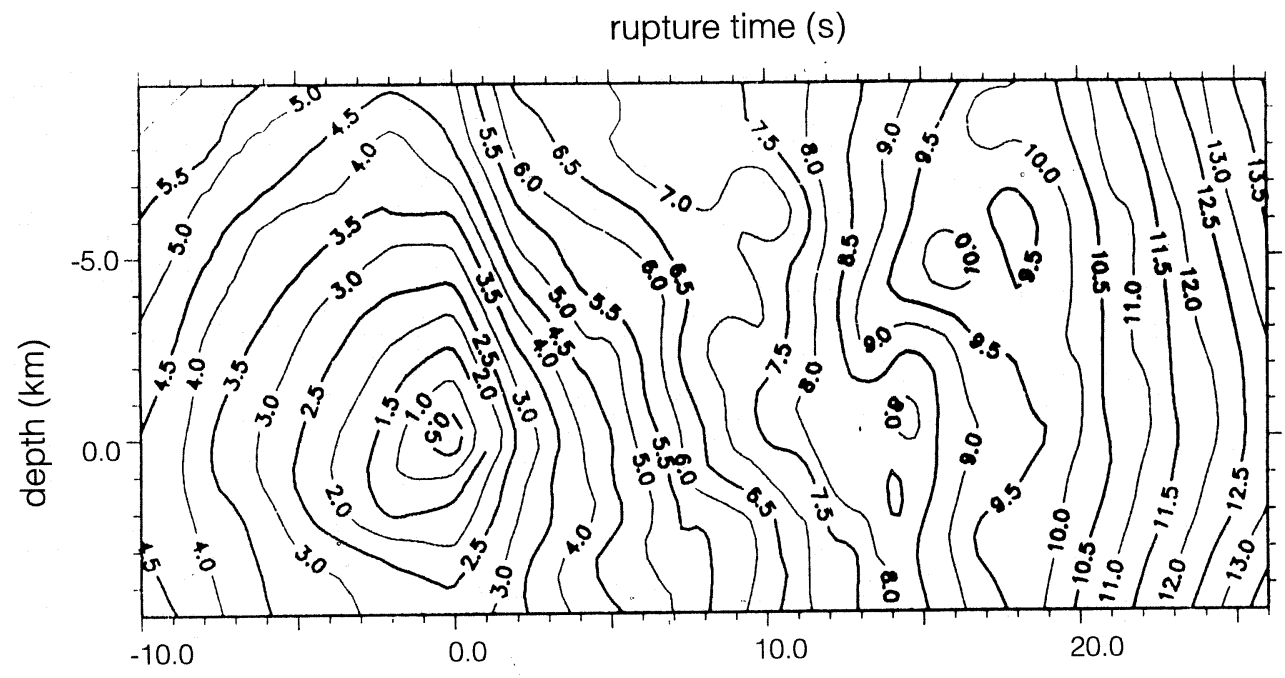

slip intensity $(\mathrm{cm} / \mathrm{s})$

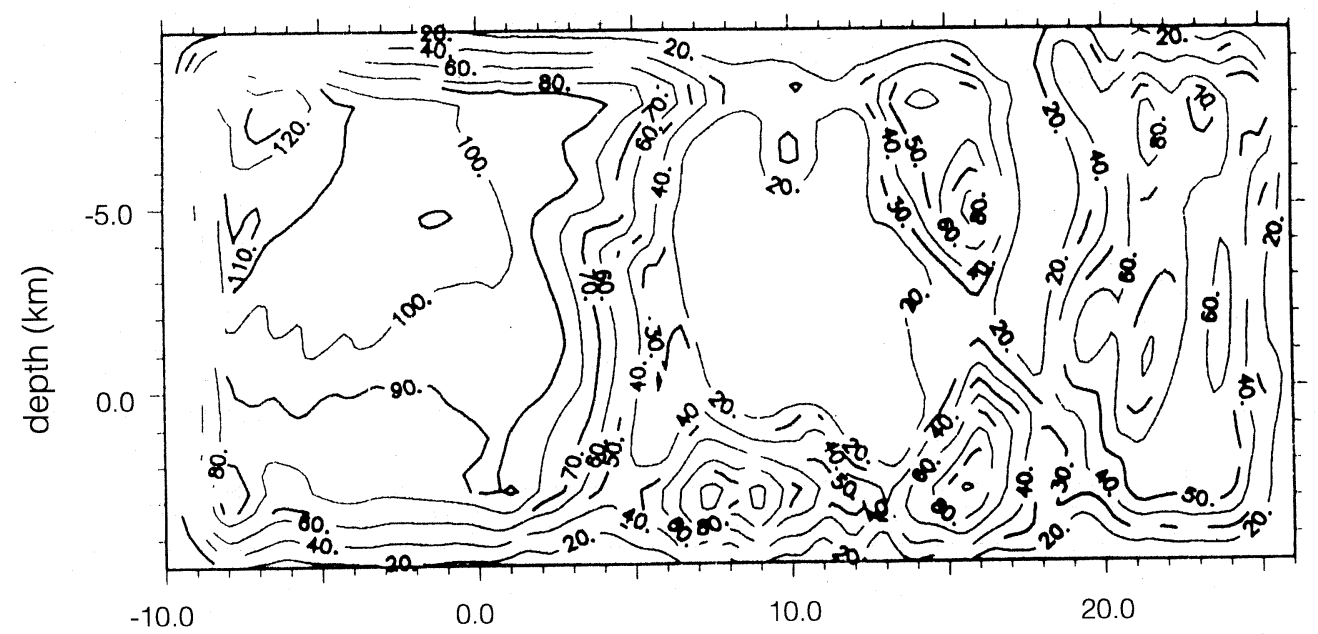

Fig. 11. Slip velocity and rupture time distribution resulting from the linearized inversion of the observed ground velocities. There are three regions of high slip velocity: the highest values are located close to the nucleation zone; the second peak of slip velocity is located $\approx 15 \mathrm{~km}$ (along the strike direction ) away from the nucleation. The last peak is located at the NW edge of the fault $(\approx 22 \mathrm{~km}$ along the strike direction $)$. Strong variations of rupture velocity are associated with these peaks of slip velocity.

slip velocity is located at the NW edge of the fault. Its absolute value is mainly constrained by the fit of the ground-motion amplitudes observed at Sturno (STU). We cannot exclude that this value could be overestimated.

The rupture time distribution consists primar- ily of a bilateral rupture propagation with variable rupture velocity. The delay time of roughly $2 \mathrm{~s}$ in the NW propagation relative to the SE rupture obtained by the forward waveform modeling is confirmed by the inversion results. A second nucleation point located $14 \mathrm{~km}$ away from 

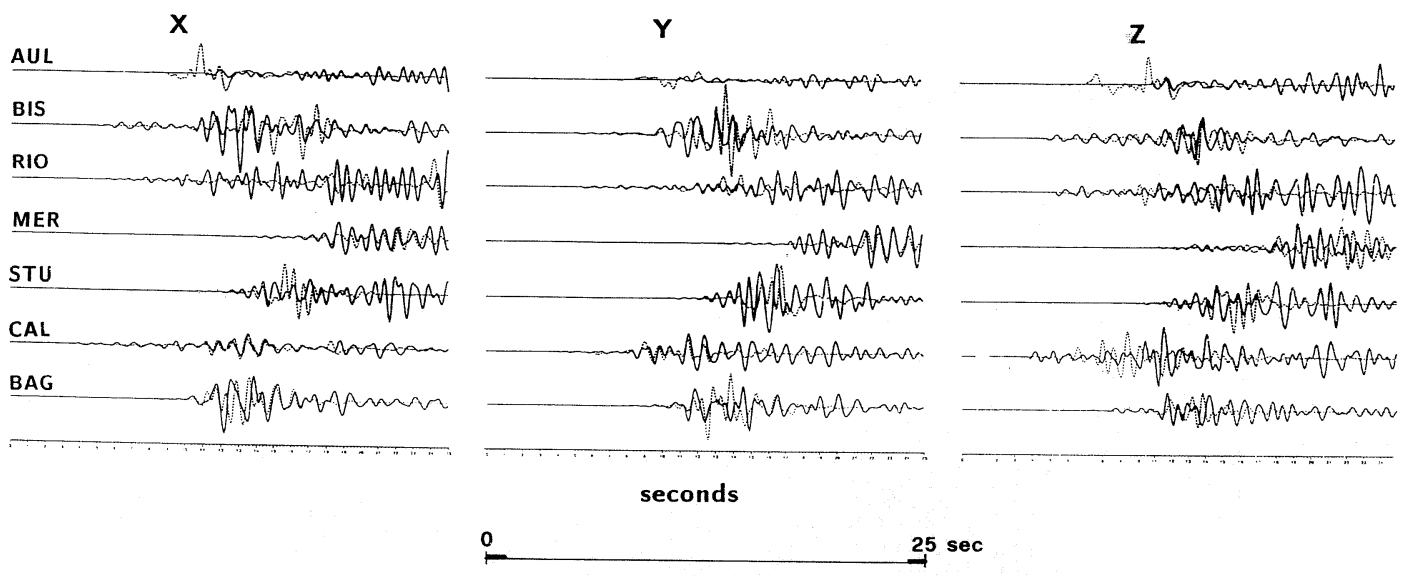

Fig. 12. Fit of the observed data (solid lines) with the synthetic seismograms (dotted lines) computed from the rupture model shown in fig. 11.

the hypocenter is also observed in fig. 11. This rupture behavior allows one to reproduce the waveforms observed at STU, BAG and CAL (fig. 12). The rupture history consists in three distinct changes in rupture velocity which are located at the places where the highest slip velocities have been found (fig. 11). This rupture model guarantees a satisfactory fit of the data: figure 12 clearly shows the $S$-wave peak on the synthetic ground velocity that triggered the accelerograph installed at AUL. The seismic moment resulting from the inversion is $1.9 \times 10^{26} \mathrm{dyne} \cdot \mathrm{cm}$ and is in close agreement with the value estimated by Bernard and Zollo (1989) for the main rupture and for the NW extension $\left(\approx 1.3 \times 10^{26}\right.$ dyne $\cdot$ $\mathrm{cm})$.

\section{Conclusions}

We have analysed the strong-motion accelerograms of the 1980 Irpinia earthquake in order to investigate the slip distribution and the rupture history during this event. The rupture model has been studied first by means of a forward waveform modeling following a trial-and-error approach, and afterwards by applying a linearized inversion of ground-motion waveforms. The forward waveform modeling and the spectral analysis of ground accelerations allowed a reliable interpretation of the strong-motion recordings enhancing the most important features of the radiated wave field. We briefly summarize the main results inferred from the forward waveform modeling.

- The amplitudes of the observed ground velocities are well reproduced by synthetic waveforms, with the exception of Mercato San Severino where a strong site effect influences the recorded ground motion.

- The rupture propagation towards the NW was delayed by about $2 \mathrm{~s}$ relative to the $\mathrm{SE}$ rupture. The total rupture duration was about 10 $\mathrm{s}$. The rupture propagated towards the NW with a more variable rupture velocity than the SE propagation.

- With the assumed fault geometry, it was not possible to fit the ground velocity at Sturno. In order to reproduce the dominant arrivals on the horizontal components we have assumed that the rupture propagated further towards the NW where no surface breakage has been observed.

The rupture model resulting from the forward approach has been used as starting model for the linearized inversion. We used a linearized tomographic inversion since our aim was to investigate slip velocity and rupture time distribution on an extended fault. Unlike other studies the fault is not subdivided into subfaults. Furthermore, the fault geometry is not a part of the solution. We 


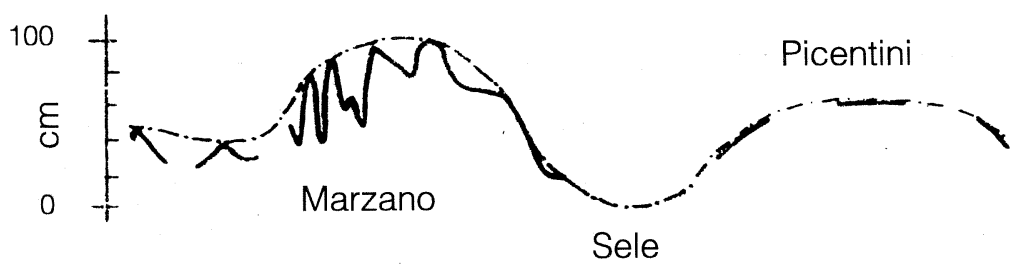

SE

Sele

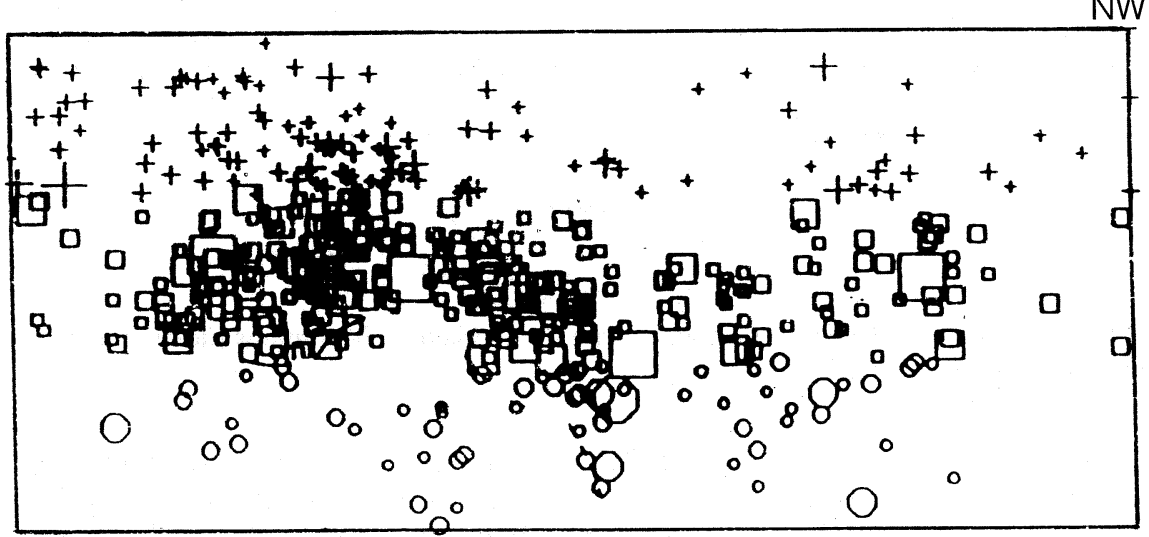

b)

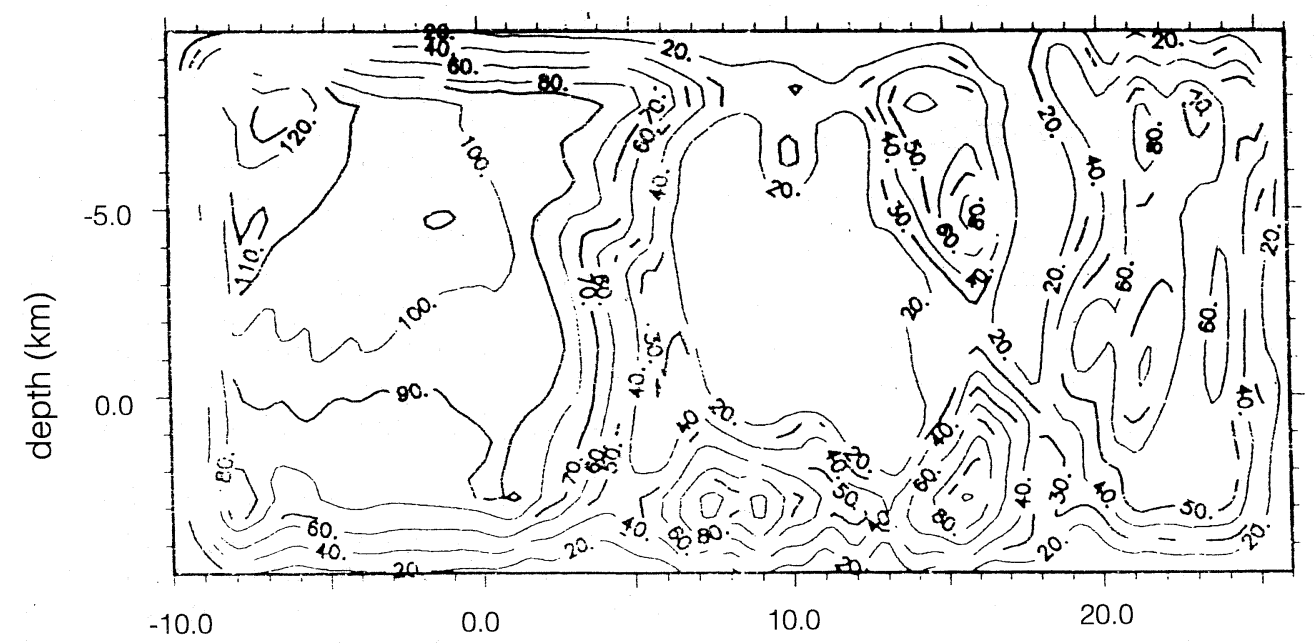

c)

distance along strike $(\mathrm{km})$

Fig. 13. Comparison between the slip velocity distribution resulting from the waveform inversion (c)), the aftershock distribution (b)) along a SE-NW cross-section (along the strike direction) and the behavior of the fault scarp height (a)) as a function of the position on the fault trace (taken from Pantosti and Valensise, 1990). The highest value of slip velocity occurs in correspondence of the largest surface breakage observed close to the nucleation (located at Marzano mountain). The gap of surface slip observed in the Sele Valley is confirmed by the inversion result. This gap corresponds to the absence of shallow seismicity in the upper $5 \mathrm{~km}$ and to a concentration of aftershocks at depth of 8 to $12 \mathrm{~km}$. The second peak of slip velocity is associated with the Picentini mountains fault scarp. No evidence of surface rupture was found at the NW edge of the fault. 
have used the results obtained in other studies (Westaway and Jackson, 1987; Bernard and Zollo, 1989; Pantosti and Valensise, 1990; Amato and Selvaggi, 1990), mainly based on independent data (such as geodetic, geologic and local seismic data), to constrain the faulting mechanism.

The results that we obtain from the waveform inversion indicate that the rupture was quite heterogeneous. The region of greatest slip velocity was close to the hypocenter. The rupture propagation towards the NW was delayed by about $2 \mathrm{~s}$ with respect to the SE one. There are two other regions of high slip velocity localized at $15 \mathrm{~km}$ and $22 \mathrm{~km}$ away from the hypocenter along the strike direction. Abrupt changes of rupture velocity occur in the source areas of high slip velocity. The behavior of slip velocity along the fault is strictly related to the fault scarp height observed at the Earth surface, and seems to be controlled by the fault zone structure. The aftershocks are concentrated mostly close to the region of maximum coseismic slip. This rupture model explains the dominant features of the rupture process on the assumed fault and the body wave field radiated at frequencies ranging between 1 and $2 \mathrm{~Hz}$.

\section{Acknowledgments}

We thank A. Amato, D. Pantosti, G. Valensise and A. Zollo for the helpful discussions and reviews of this paper. We would also like to thank G. Beroza and P. Spudich for providing their computer programs. We thank D. Riposati for drawing many of the figures. This research was completely supported by the internal research funds of ING.

$\left(^{*}\right)$ Now at ISMES Laboratory, Bergamo, Italia.

\section{REFERENCES}

Alessandrini, B., A. Rovelli, M. Cocco and S. Mazza (1990): Computation of ground displacement from strong-motion accelerograms using the exact deconvolution technique, Bull. Seismol. Soc. Am., 80, 1753-1761.

Amato, A., M. Cocco, D. Pantosti and G. Valensise (1989): Investigating a complex earthquake with a multi- disciplinary approach: the 1980, Irpinia, normal faulting event (MS 6.9), EOS Transactions A.G.U., 70, 1226.

Amato, A. and G. SelvagGi (1990): Aftershock relocation and crustal structure in the epicentral region, Preprints of the Proceedings of the International Meeting "Irpinia Dieci Anni Dopo», Sorrento, November 1990, pp. 34-39.

ANDERSon, J.G. and S.E. Hough (1984): A model for the shape of the Fourier amplitude spectrum of acceleration at high frequencies, Bull. Seismol. Soc. Am., 74, 19691993.

BEROZA, G.C. and P. SPUDICH (1988): Linearized inversion for fault rupture behavior: application to the 1984 Morgan Hill, California, earthquake, J. Geophys. Res., 93, 62756296.

Bezzeghoud, M..(1987): Inversion et analyse spectrale des ondes $P$, These de doctorat de l'Universite Paris VII, France.

BERNARD, P. and A. ZoLlo (1988): Inversion of $S$ polarization from near-source accelerograms. Application to the records of the 1980 Irpinia earthquake, in Proceedings of the Summer School «Seismic Hazard in Mediterranean Regions», Strasbourg 1986, edited by J. BonNIN et al., (Kluwer Academic Publishers, Dordrecht), pp. 59-69.

BERNARD, P. and A. Zollo (1989): The Irpinia (Italy) 1980 earthquake: detailed analysis of a complex normal fault, J. Geophys. Res., 94, 1631-1648.

Boschi, E., F. Mulargia, E. Mantovani, M. Bonafede, A. M. DZIEWONSKI and J.H. WOODHOUSE (1981): The Irpinia earthquake of November 23, 1980 (abstr.), EOS Transactions A.G.U., 62, 330 .

BRUSTLE, W. and G. MülLER (1983): Moment and duration of shallow earthquakes from Love-wave modeling for regional distances, Phys. Earth Planet. Int., 32, 312-324.

Crosson, R.S., M. MARTINI, R. SCARPA and S.C. KEY (1986): The Southern Italy earthquake of 23 November 1980: an unusual pattern of faulting, Bull. Seismol. Soc. Am., 76, 395-407.

DAY, S.M. (1982): Three-dimensional finite difference simulation of fault dynamics: rectangular faults with fixed rupture velocity, Bull. Seismol. Soc. Am., 72, 705-727.

Del Pezzo, E., G. Iannaccone, M. Martini and R. Scarpa (1983): The 23 November 1980 Southern Italy earthquake, Bull. Seismol. Soc. Am., 73, 187-200.

GIARDINI, D. (1990): The November 23, 1980 Irpinia earthquake: teleseismic observations, Preprints of the Proceedings of the International Meeting «Irpinia Dieci Anni Dopo», Sorrento, November 1990, pp. 19-24.

Giardini, D., A.M. DzIEWONSKI, J.H. WoOdHouse and E. BoschI (1984): Systematic analysis of the seismicity of the Mediterranean region using the centroid-moment tensor method, in The O.G.S. Silver Anniversary Volume, edited by A. BRAMBATI and D. SLEJKo, pp. 121-142.

IVANSON, S. (1983): Remark on an earlier proposed tomographic algorithm, Geophys. J. R. Astron. Soc., 75, 855860 .

KANAMORI, H. and J.W. GIVEN (1982): Use of long-period surface waves for rapid determination of earthquake source parameters, 2 . Preliminary determination of source mechanisms of large earthquakes $\left(M_{\mathrm{S}} \geq 6.5\right)$ in 1980 , Phys. Earth Planet. Int., 30, 260-268.

KING, G.C.P. (1986): Speculations on the geometry of the initiation and termination of earthquake rupture and its 
relation to morphology and geological structure, Pure Appl. Geophys., 124, 567-585.

KosTrOV, B.V. (1966): Self-similar problems of propagation of shear cracks, J. Appl. Math. Mech., 28, 1077-1087.

MADARIAGA, R. (1976): Dynamics of an expanding circular fault, Bull. Seismol. Soc. Am., 66, 639-666.

Marone, C. and C.H. Scholz (1988): The depth of seismic faulting and the upper transition from stable to unstable slip regimes, Geophys. Res. Lett., 15, 621-624.

NAKANISHI, I. and H. KANAMORI (1984): Source mechanisms of twenty-six large earthquakes $\left(M_{S} \geq 6.5\right)$ during 1980 from $P$-wave first motion and long-period Rayleigh wave data, Bull. Seismol. Soc. Am., 74, 805-818.

OLSON, A.H. (1987): A Chebyshev condition for accelerating convergence of iterative tomographic method - solving large least square problems, Phys. Earth Planet. Int., 47, 333-345.

PANTOSTI, D. and G. VALENSISE (1990): Faulting mechanism and complexity of the 23 November, 1980, Campania-Lucania earthquake inferred form surface observations, $J$. Geophys. Res., 95, 15319-15341.

Rovelli, A., O. Bonamassa, M. CocCo, M. DI Bona and S. MAZZA (1988): Scaling laws and spectral parameters of the ground motion in active extensional areas in Italy, Bull. Seismol. Soc. Am., 78, 530-560.
SIRO, L. and C. CHIARUTTINI (1989): Source complexity of the 1980 southern Italian earthquake from the analysis of strong-motion $S$-wave polarization, Bull. Seismol. Soc. Am., 79, 1810-1832.

SPUDICH, P. and L.N. FRAZER (1984): Use of the ray theory to calculate high frequency radiation from earthquake source having spatially variable rupture and stress drop, Bull. Seismol. Soc. Am., 74, 2061-2082.

SuHadolc, P., P. Harabaglia and G.F. PAnZa (1990): Deterministic modeling and estimate of strong ground motion: the Irpinia, Italy, November 23, 1980 earthquake, Proceedings of the Ninth European Conference on Earthquake Engineering, Moscow 1990, Vol. 4a, pp. 110-120.

ThuRBER, C.H. (1983): Earthquake locations and threedimensional crustal structure in the Coyote Lake area, Central California, J. Geophys. Res., 88, 8226-8236.

TSE, S.T. and J.R. RICE (1986): Crustal earthquake instability in relation to the depth variation of frictional slip properties, J. Geophys. Res., 91, 9452-9472.

WESTAWAY, R. and J. JACKSON (1984): Surface faulting in the southern Italian Campania-Basilicata earthquake of 23 November 1980, Nature, 312, 436-438.

WESTAWAY, R. and J. JACKSON (1987): The earthquake of 1980 November 23 in Campania-Basilicata (Southern Italy), Geophys. J. R. Astron. Soc., 90, 375-443. 